\title{
Olivine-induced viscous anisotropy in fossil strike-slip mantle shear zones and associated strain localization in the crust
}

\author{
Published in the journal Geophysical Journal International (GJI) \\ DOI: $10.1093 / \mathrm{gji} / \mathrm{ggaa} 400$ \\ Lucan Mameri $^{\mathrm{a}}$, Andréa Tommasi $^{\mathrm{a}}$, Javier Signorelli $^{\mathrm{b}}$, Riad Hassani $^{\mathrm{c}}$ \\ ${ }^{a}$ Géosciences Montpellier - CNRS \& Université de Montpellier, France

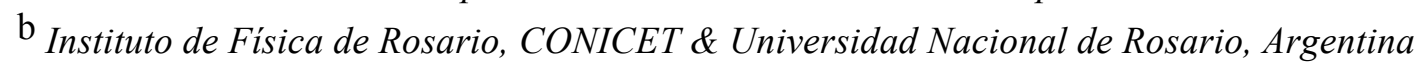 \\ c Géoazur, Observatoire de la Côte d'Azur, Université Côte d'Azur, France
}

\begin{abstract}
We propose that strain localization in plate interiors, such as linear belts of intraplate seismicity, may arise from spatial variations in viscous anisotropy produced by preferred orientation of olivine crystals (CPO or texture) inherited from previous deformation episodes in the lithospheric mantle. To quantify this effect, we model the deformation of a plate containing a fossil strike-slip mantle shear zone at different orientations relative to an imposed shortening, but no initial heterogeneity in the crust. The fossil shear zone is characterized by different orientation and intensity of the olivine CPO relatively to the surrounding mantle, which is isotropic in most simulations. The anisotropy in viscosity produced by the $\mathrm{CPO}$, which remains fixed throughout the simulations, is described by an anisotropic (Hill) yield function parameterized based on second-order viscoplastic selfconsistent (SO-VPSC) models. The results indicate that lateral variations in viscous anisotropy in the mantle affect the strain distribution in the entire lithosphere. Reactivation of the mantle shear zone and strain localization in the crust above it occur for compression at 35$55^{\circ}$ to the mantle shear zone, with a maximum at $45^{\circ}$. The magnitude of strain localization depends on (i) the contrast in viscous anisotropy and, hence, on the CPO orientation and intensity in the mantle domains, (ii) the boundary conditions, and (iii) the feedbacks between mantle and crustal deformation. For a strong olivine CPO, when the boundary conditions do not hinder shear parallel to the fossil mantle shear zone, strain rates within it are up to 30 times higher than in an isotropic surrounding mantle or up to 200 times when the surrounding mantle is anisotropic, which results in strain rates up to 10 times or up to 100 times higher in the crust above the fossil shear zone. Frictional weakening in the crust faults increases strain localization in the entire lithospheric column. High strength contrasts between the mantle and the ductile crust result in less efficient coupling, with strong localization in the mantle and lower crust, but weak in the brittle upper crust. Decrease in the crust-mantle strength contrast enhances coupling and produces more homogenous strain distribution with depth, as well as a time-dependent evolution of strain localization, which reaches a peak and decreases before attaining steady-state. Comparison of seismic anisotropy, regional stress, and focal mechanism data in linear arrays of intraplate seismicity, like the New Madrid and South Armorican seismic zones, to our models' predictions corroborates that olivine CPO preserved in fossil lithospheric-scale shear zones may be key for the development of such structures.
\end{abstract}

Keywords: Creep and deformation; Mantle processes; Intra-plate processes; Rheology: crust and lithosphere; Numerical modeling; Continental tectonics: strike-slip and transform; 


\section{Introduction}

In intraplate domains, olivine crystallographic preferred orientations (CPO) formed during previous collisional or rifting events might be preserved for long time-spans. Directional dependence of the mantle viscosity due to olivine CPO fossilized in the lithospheric mantle, particularly that formed in large-scale strike-slip shear zones in collisional belts, has been argued to influence the deformation of continental plates, producing structural reactivation of fossil mantle structures when subsequent stress fields generate high resolved shear stresses on them (Tommasi and Vauchez 2001; Vauchez et al. 1997; Vauchez et al. 1998).

The parallelism between the directions of fast shear-wave polarization, linear seismicity arrays, and inherited tectonic structures extending for several hundreds of kilometres in intraplate domains, as in the New Madrid (Tuttle et al. 2002; Nyamwandha and Powell 2016) and South Armorican seismic zones (Judenherc 2000; Judenherc et al. 2003; Mazabraud et al. 2005a; Mazabraud et al. 2005b), suggests a causal relation between CPO-induced viscous anisotropy in the lithospheric mantle and strain localization in the crust. However, there is a lack of studies addressing quantitatively the role of olivine viscous anisotropy on crustal deformation that could support this view. Here, we model the viscous anisotropy associated with fossil strike-slip mantle shear zones and the resulting strain localization in the entire continental lithosphere. The key questions are: (1) whether lateral variations in the (orientation and intensity of) olivine CPO within the mantle suffices to trigger strain localization in otherwise stable intraplate domains, and (2) which is the degree and pattern of strain localization in both the crust and mantle.

Olivine is the most abundant and deformable rock-forming mineral in the lithospheric mantle. The olivine crystal displays a marked viscous anisotropy because it has only three independent slip systems to accommodate dislocation creep and because these slip systems have markedly different strengths. At high temperature and moderate pressure, olivine crystals may deform $>100$ times faster if their orientation allow for deformation by dislocation glide on the easy (010)[100] slip system rather than on the hard (010)[001] slip system (Durham and Goetze 1977; Bai et al. 1991). This viscous anisotropy is transferred to the rock-scale through the development of CPO (Nicolas and Christensen 1987). However, as the CPO has always some dispersion, the rock-scale anisotropy is significantly weaker than that of a single crystal. Activation of grain-boundary related processes in addition to intracrystalline glide further reduces the magnitude of viscous anisotropy, in particular in 
fine-grained rocks. For instance, in laboratory experiments under constant strain rate, finegrained olivine polycrystals deformed in simple shear parallel to a previous shear direction and plane exhibit stresses $\sim 2$ times lower than those needed for deforming the polycrystals in extension perpendicular to the previous shear plane (Hansen et al. 2012). Polycrystal plasticity simulations carried out under equivalent boundary conditions and using exactly the same olivine CPOs showed that, if only dislocation creep is considered, the contrast between simple shear and extension yield stresses increases to a factor $\sim 6$ (Mameri et al. 2019). These studies demonstrated that the viscous anisotropy at the rock-scale depends on the CPO symmetry and intensity, on the imposed boundary conditions, as well as on the relative contributions of dislocation and grain-boundary mechanisms to viscoplastic deformation.

May this CPO-induced viscous anisotropy produce strain localization at the scale of tectonic plates? Based on viscoplastic self-consistent (VPSC) simulations of the viscous anisotropy of olivine polycrystals, Tommasi and Vauchez (2001) concluded that oblique load on a CPO formed in response to a previous strike-slip deformation was likely to produce structural reactivation of collisional belts during plume-triggered rifting and that this reactivation was characterized by deformation in transtension. By coupling VPSC simulations to a finite-element model, Knoll et al. (2009) and Tommasi et al. (2009) proposed that CPOinduced viscous anisotropy in the lithospheric mantle may play an essential role in the deformation patterns at the plate tectonic scale. For instance, when the fossil olivine CPO in the mantle is oriented oblique to the imposed extension, the associated anisotropic viscosity induces strain localization and enhances toroidal flow, leading to transtensional rifting. These fully coupled models provided quantitative estimates of the effects of viscous anisotropy associated with strain-induced CPO in the lithospheric mantle. However, they were very timeconsuming.

In the present work, we developed a parameterization of the anisotropic viscosity of olivine based on the prediction of VPSC simulations, which used relative slips system strengths derived from high temperature experiments in olivine single crystals, and implemented it in a 3D finite-element geodynamical code to model the anisotropic deformation of the mantle due to fossil olivine CPO and the mechanical response of the crust to this deformation. We evaluate how the mechanical response of a continental plate is affected by lateral variations in olivine CPO (orientation and intensity), by the boundary conditions, and by the mechanical interplay between crust and mantle deformation related to their strength contrast. The aim is to test whether CPO-induced viscous anisotropy associated 
with a fossil strike-slip mantle shear zone may trigger strain localization in the entire lithosphere, giving rise for instance to linear arrays of intraplate seismicity, as the New Madrid and South Armorican seismic zones.

\section{Numerical modelling}

We use the 3D thermo-mechanical finite-element code Adeli3D (Hassani 1994) to model lithospheric-scale deformation. The code is based on a Lagrangian discretization of the quasi-static mechanical behavior of the lithosphere, which solves the obtained non-linear equations using a dynamic relaxation method (Cundall and Board 1988).

The elasto-viscoplastic deformation is given by:

$$
\left\{\begin{array}{c}
\boldsymbol{\sigma}^{*}=2 \mu\left(\mathbf{D}-\mathbf{D}_{\boldsymbol{v}}\right) \\
\dot{p}=3 K \operatorname{tr}(\mathbf{D})
\end{array}\right.
$$

where $\mathbf{D}$ and $\mathbf{D}_{v}$ are the total and viscoplastic strain rate tensors, $\boldsymbol{\sigma}^{*}$ is the objective material derivative of the Cauchy stress tensor, $p$ is the mean pressure, $\mu$ and $K$ are the shear and bulk moduli, respectively. The equations are solved forward in time $\left[t^{n}, t^{n+1}\right]$ using a CrankNicholson scheme that assumes D constant over the timestep. Further details can be found in Chéry et al. (2001). The crust is elasto-viscoplastic. Frictional (brittle-plastic) behaviour in the upper crust obeys an isotropic Drucker-Prager yield criterion written as:

$$
\mathcal{F}(\boldsymbol{S})=J_{2}(\mathbf{S})+\alpha(p-c / \tan \phi) \leq 0
$$

In this form, the second $\left(2^{\text {nd }}\right)$ invariant of the deviatoric stress tensor $\mathbf{S}$ corresponds to the Von Mises equivalent stress: $J_{2}(\mathbf{S})=\left(\frac{3}{2} \mathbf{S}: \mathbf{S}\right)^{1 / 2}, \phi$ is the static internal angle of friction, $c$ is the cohesion, and $\alpha$ is a material parameter related to $\phi$ by $\alpha=6 \sin \phi /(3-\sin \phi)$. Frictional weakening may be imposed by decreasing the angle of friction after $1 \%$ of plastic strain in the mesh element. Thermally activated viscous creep follows a power law relationship in the form:

$$
\mathbf{D}_{v}=\gamma \exp \left(-\frac{Q}{R T}\right) J_{2}(\mathbf{S})^{n-1} \mathbf{S}
$$

where $n, Q$, and $\gamma$ are the experimentally-derived power law exponent, activation energy in $\mathrm{kJ}$ $\mathrm{mol}^{-1} \mathrm{~K}^{-1}$, and fluidity in $\mathrm{Pa}^{-\mathrm{n}} \mathrm{s}^{-1}$, respectively. $R$ is the gas constant and $T$ is temperature in 
degrees Kelvin. To simulate viscous anisotropy in the mantle, Eq. (3) was extended as:

$$
\mathbf{D}_{v}=\gamma \exp \left(-\frac{Q}{R T}\right) J_{h}(\mathbf{S})^{n-1} \mathbf{A}_{h}: \mathbf{S}
$$

where $J_{h}(\mathbf{S})$ is the Hill equivalent stress (Hill 1948) defined as:

$$
J_{h}(\mathbf{S})=\left(F\left(S_{11}-S_{22}\right)^{2}+G\left(S_{22}-S_{33}\right)^{2}+H\left(S_{33}-S_{11}\right)^{2}+2 L S_{12}^{2}+2 M S_{23}^{2}++2 N S_{31}^{2}\right)^{1 / 2}
$$

Using the Voigt notation, the components of the stress and strain rate tensors are collected into 6-dimensional vectors. In this notation, $\mathbf{A}_{h}$ is a rank-4 tensor describing the material anisotropy, which has the following matrix representation:

$$
\mathbf{A}=\mathbf{A}_{h}=\frac{2}{3}\left[\begin{array}{cccccc}
F+H & -F & -H & 0 & 0 & 0 \\
-F & G+F & -G & 0 & 0 & 0 \\
-H & -G & H+G & 0 & 0 & 0 \\
0 & 0 & 0 & L & 0 & 0 \\
0 & 0 & 0 & 0 & M & 0 \\
0 & 0 & 0 & 0 & 0 & N
\end{array}\right]
$$

The Hill yield function (Eq. 5) must be defined in the reference frame of the CPO eigenvectors, which has to be orthotropic. The Hill parameters $(F, G, H, L, M, N)$ for a given olivine CPO are evaluated using the second-order viscoplastic self-consistent (SO-VPSC) model as described in the next section. The isotropic case, i.e., $J_{h}(\mathbf{S})=J_{2}(\boldsymbol{S})$ and $\mathbf{A}_{h}: \mathbf{S}=\mathbf{S}$, is retrieved by setting $F=G=H=1 / 2$ and $L=M=N=3 / 2$; this reduces Eq. (4) to Eq. (3).

Parameterizing the CPO-induced viscous anisotropy of olivine polycrystals

The viscoplastic mechanical response of an olivine polycrystal with a given $\mathrm{CPO}$ is calculated using the SO-VPSC model (Ponte Castañeda 2002; Lebensohn et al. 2011). The response is defined in the stress-space as an equipotential surface for a series of mechanical tests in which we impose the deviatoric stress tensor and determine the associated strain rate tensor. All simulations are run for olivine polycrystals composed by 1000 grains. The slip systems data are derived from experiments at high temperature and moderate pressure conditions (Table 5.1). We sample different loading paths (simple shear, pure shear, axial compression or tension) and vary the orientation of the stress tensor relatively to the CPO reference frame by $15^{\circ}$ intervals. For defining properly the equipotential surface, the mechanical responses for all evaluated loading paths are normalized by the work rate of 
a polycrystal that has an isotropic response. A least-square method is used to fit the equipotential surfaces and calibrate the six parameters $(F, G, H, L, M, N)$ that satisfy the anisotropic Hill yield function (Eq. 5).

Table 1: Olivine slip systems parameters used in the SO-VPSC simulations

\begin{tabular}{ccc}
\hline $\begin{array}{c}\text { Slip } \\
\text { Systems }\end{array}$ & $\begin{array}{c}\text { Critical Resolved } \\
\text { Shear Stress \# }\end{array}$ & Stress Exponent \\
\hline$(010)[100]$ & 1 & 3 \\
$(001)[100]$ & 1 & 3 \\
$(010)[001]$ & 2 & 3 \\
$(100)[001]$ & 3 & 3 \\
$(011)[100]$ & 4 & 3 \\
$(110)[001]$ & 6 & 3 \\
$\{111\}<110>^{\text {a }}$ & 50 & 3 \\
$\{111\}<011>^{\text {a }}$ & 50 & 3 \\
$\{111\}<101>^{\text {a }}$ & 50 & 3 \\
\hline \# Adimensional values; normalized by the flow stress of the $(010)[100]$ \\
slip system. ${ }^{\text {a }}$ Slip systems not active in olivine, used solely for stabilizing \\
the calculations and accommodating $<<5 \%$ strain in all simulations.
\end{tabular}

We estimate the viscous anisotropy for olivine polycrystals with an orthorhombic $\mathrm{CPO}$, which is expected to develop by simple shear or combinations of simple and pure shear (Tommasi et al. 1999), and two different CPO intensities. The intensity of the olivine CPO is quantified by the $\mathrm{J}$ - or $\mathrm{M}$-indexes calculated based on the orientation distribution function defined using a "de la Vallée Poussin" kernel with a halfwidth of $10^{\circ}$ (Mainprice et al. 2014). The J-index may range from 1 (random) to infinite (single-crystal orientation) and the M-index from 0 to 1 . The two CPO investigated in this study are characterized by a J-index of $2.8(\mathrm{M}$-index $=0.12$, weak CPO $)$ and of $12.7(\mathrm{M}$-index $=0.42$, strong $\mathrm{CPO})$. For the sake of comparison, olivine polycrystals deformed in torsion to shear strains between 3 and 19 display J-indexes between 9 and 23, with a median at $\sim 13$ and two outliers at 5 and 30 (Hansen et al. 2014). The median of $>600 \mathrm{~J}$-index measurements in naturally deformed peridotites is $\sim 4$ and the maximum is $\sim 20$ (Tommasi and Vauchez 2015).

Two-dimensional projections of the equipotential surfaces used for calculating the Hill parameters for olivine polycrystals with a random and the weak and strong investigated CPO are presented in Figure 1. The aspect ratio of the projections is proportional to the magnitude 
of the viscous anisotropy. The isotropic response (random CPO, J-index $=1$ ) is characterized by circular projections (aspect ratio of 1:1). The projections become more elliptical as the strength of the CPO increases. For the olivine CPO used here, the maximum aspect ratio is observed in the S1-S5 projection, where flow stress for a pure-shear test with traction parallel to the [010]-maximum of the $\mathrm{CPO}$ is a factor $\sim 6$ larger than the flow stress for a simple-shear test with shear parallel to the [100]-maximum on the plane normal to the [010]-maximum. The mathematical formalism and the numerical implementation of the parameterized viscous anisotropy in the code Adeli3D-anis are detailed in a companion article (Signorelli et al. submitted).
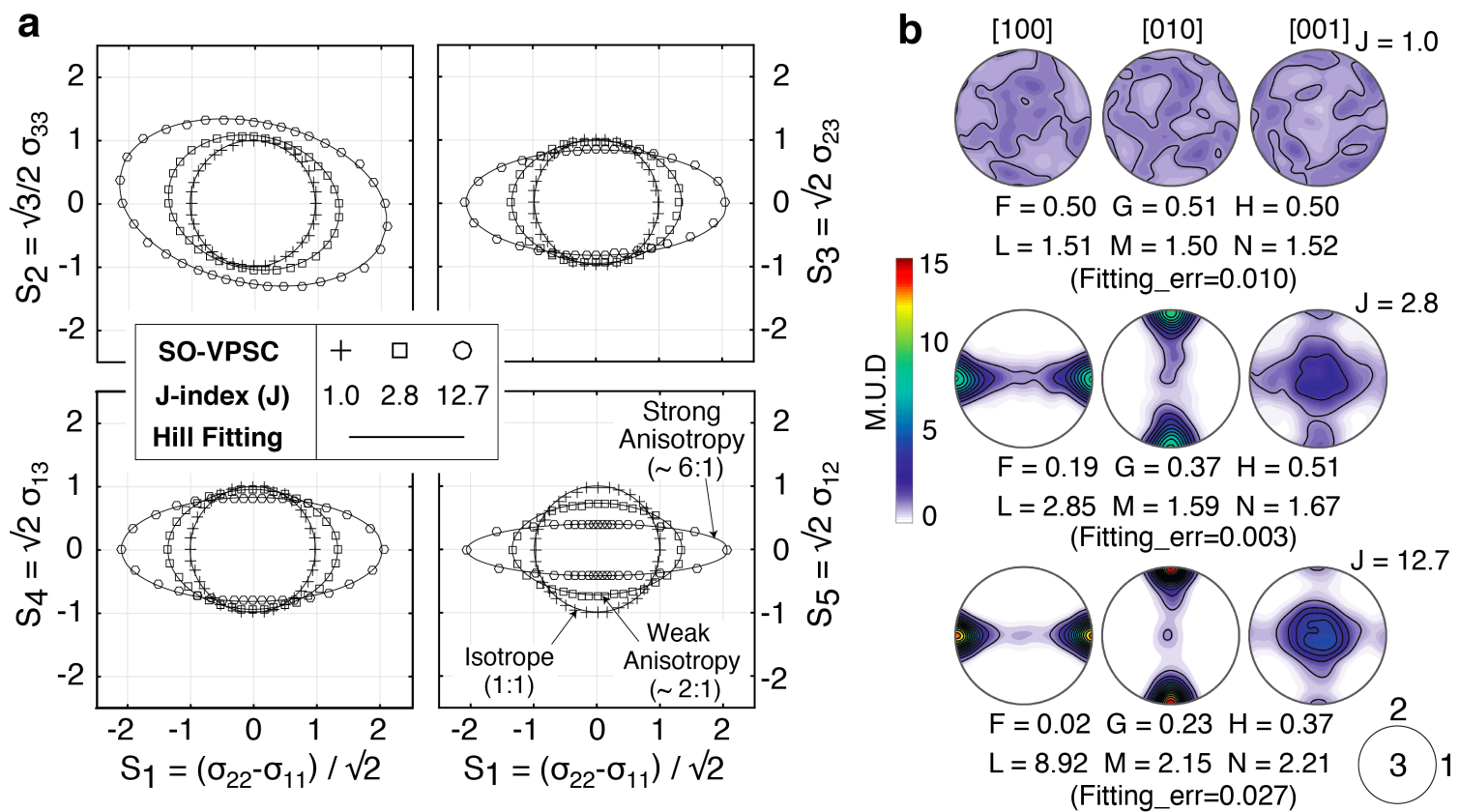

Figure 1: a) Projections of the equipotential surface predicted by SO-VPSC simulations (black lines) and the least-squares fit (black markers) used for defining the Hill parameters (F, $\mathrm{G}, \mathrm{H}, \mathrm{L}, \mathrm{M}$, and $\mathrm{N}$ ) for the three olivine CPOs used in the present simulations, which are presented in (b). The aspect ratio of the projections is proportional to the intensity of the viscoplastic anisotropy. The misfit between the SO-VPSC predictions and the Hill fitting is in all cases $\ll 0.1$. Pole figures are contoured at one multiple of uniform distribution intervals. Insert on the bottom right shows the relation between the CPO and the SO-VPSC reference frames.

\section{Geodynamical model setup}

\section{Geometry and boundary conditions}

The model has a heterogeneous mantle and a homogenous crust (Figure 2). It simulates a $1100 \mathrm{~km}$ long, $500 \mathrm{~km}$ wide, and $120 \mathrm{~km}$ deep continental plate containing a fossilized mantle shear zone marked solely by a change in the orientation and intensity of the 
olivine CPO in the lithospheric mantle. The model has therefore three domains: (1) a $40 \mathrm{~km}$ thick crust and (2) an $80 \mathrm{~km}$-thick mantle layer, which is subdivided into (2a) a $50 \mathrm{~km}$-wide vertical fossil mantle shear zone that has an olivine CPO consistent with a previous strike-slip deformation, and (2b) the surrounding mantle, which in most simulations has a random CPO. Simulations were also performed using a non-random CPO in the surrounding mantle, with a different orientation than in the fossil mantle shear zone. Crustal thickness is based on global models of velocity and density of the lithosphere, which predict crustal thicknesses of $\sim 35-45$ $\mathrm{km}$ in most continents (Mooney 2015). Lithospheric thickness is based on heat flow and seismic measurements, which imply that, outside cratons, the lithosphere in stable continental plates is on average 100-150 kilometres thick (Steinberger and Becker 2018). The direction of the fossil mantle shear zone relative to the imposed horizontal shortening in the reference simulation is of $45^{\circ}$; this angle ( $\theta$, called here loading-geometry) is varied between $30^{\circ}$ and $90^{\circ}$ in the different simulations. The dip of the fossil shear zone is vertical in all simulations. To simulate fossil mantle shear zones at $\theta<30^{\circ}$ that do not crosscut the boundary on which the shortening is applied the simulation box has to be considerably lengthened. This results in a significant increase of computing time. Thus, the mechanical response at these loadinggeometries was inferred based on the prediction for the complementary orientation (e.g., $\theta=30^{\circ} \approx \theta=60^{\circ}$ ), as previous studies show that polycrystals with orthorhombic olivine CPOs, such as those used here, display a quasi-symmetric deformation pattern relative to the loading-geometry (Tommasi and Vauchez 2001).

A constant compressional velocity of $1.10^{-9} \mathrm{~m} / \mathrm{s}(\sim 3 \mathrm{~cm} / \mathrm{y})$ imposed normal to the left lateral boundary drives the plate kinematics (Figure 2). Free-slip conditions are imposed to the right lateral boundary. This results in $<10 \%$ of bulk shortening along the Y direction after $\sim 2.5$ m.y. Gravity-induced body forces are considered. The upper boundary is free and lithostatic pressure conditions (Winkler-like) are imposed to the bottom boundary. In most simulations, lithostatic pressure conditions (P-litho) are imposed to the front and back lateral boundaries, but free-slip conditions were also tested. These two sets of lateral boundary conditions correspond to different strengths of the adjacent lithosphere, free-slip conditions simulating an undeformable domain, such as a cold craton, and lithostatic pressure conditions, a neighbouring domain with similar strength to that of the simulation box. Constant temperatures of $25^{\circ} \mathrm{C}$ and $1200^{\circ} \mathrm{C}$ are applied at the top and bottom boundaries of the model, with the Moho discontinuity at $600^{\circ} \mathrm{C}$ and linear temperature gradients in the crust and mantle. Heat flux is null at all boundaries. The models are discretized in $c a$. 480,000 
tetragonal elements, which are on average $5 \mathrm{~km}$ wide in the crust and $10 \mathrm{~km}$ wide in the mantle. Further increasing the mesh resolution does not significantly change the model predictions at steady-state (Supplementary material Figure S1).

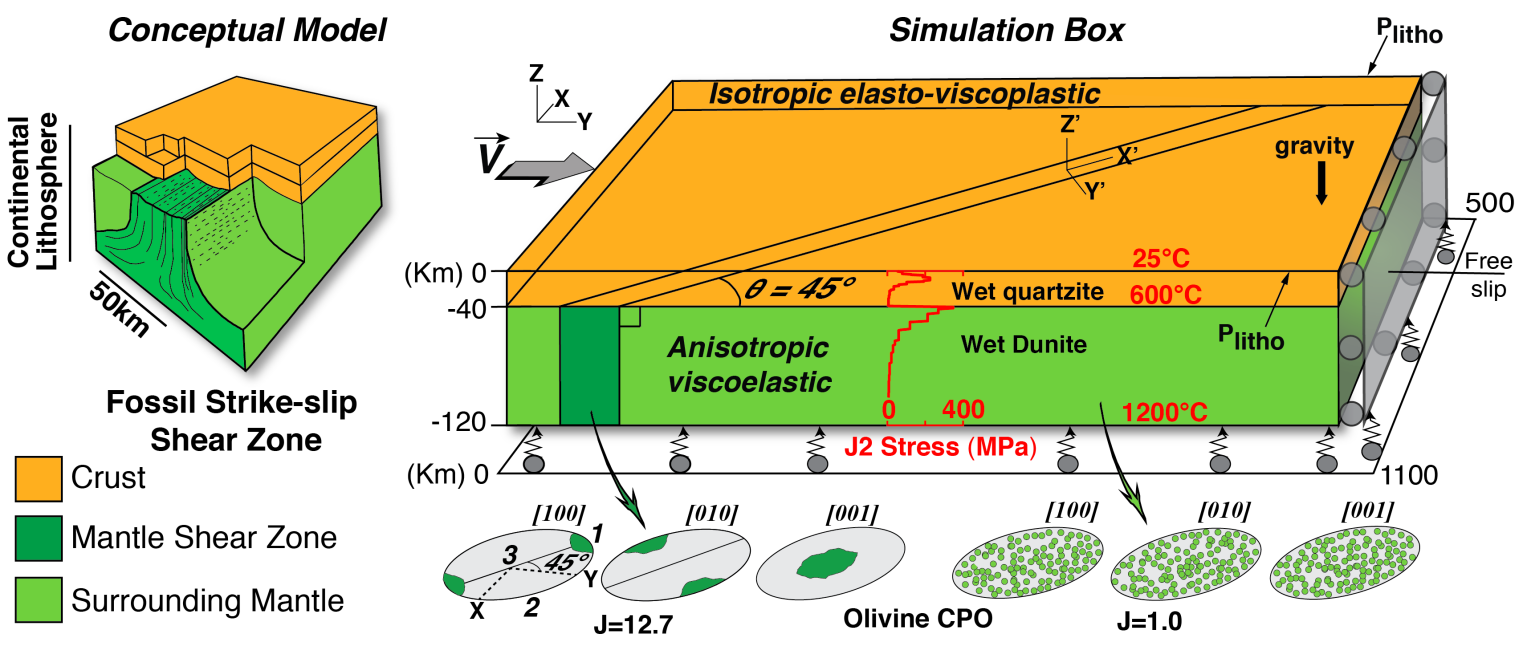

Figure 2: Setup for simulating the compressional deformation of a continental plate containing a $50 \mathrm{~km}$ wide fossil strike-slip shear zone in the upper mantle, but a homogenous crust. The mantle shear zone displays an olivine CPO consistent with seismic anisotropy measurements in lithospheric-scale strike-slip shear zones, characterized by maximum concentrations of olivine [100]- and [010]-axes horizontal, respectively parallel and normal to the shear zone trend, and a vertical alignment of [001]-axes (Vauchez and Nicolas, 1991). The orientation of the mantle shear zone relatively to the imposed compression axis $(\theta$, loading-geometry) varies between $30^{\circ}$ and $90^{\circ}$. In the reference case presented here, the preexisting mantle shear zone is at $45^{\circ}$ to the shortening direction $\left(\theta=45^{\circ}\right)$ and has a strong olivine CPO $(\mathrm{J}=12.7)$, whereas the surrounding upper mantle has a random CPO $(\mathrm{J}=1.0)$. The external (XYZ) and mantle shear zone (X'Y'Z') reference frames are shown on the top view of the simulation box, and the lithospheric strength profile, the temperature and lateral boundary conditions used in the reference simulation in the lateral view. Average mesh sizes in the crust and mantle are 5 and $10 \mathrm{~km}$, respectively.

\section{Material behaviour and olivine CPO}

In most models the crust has a homogeneous composition, but some simulations were run either with a two-layer crust or without the crust. We chose a static internal angle of friction $(\phi)$ of $30^{\circ}$ and low cohesive strength of $10 \mathrm{MPa}$ to simulate the behaviour of the brittle upper crust in a stable continental region containing a large number of faults formed in previous tectonic episodes (Townend and Zoback 2000). In some models, frictional weakening is imposed to the crust faults by reducing $\phi$ to a final angle of friction $\phi_{f}(=$ $15^{\circ}, 10^{\circ}$, or $5^{\circ}$ ) when the plastic strain in the crustal mesh element exceeds $1 \%$. This final angle of friction remains fixed thereafter (i.e., no fault healing). The rheology of the viscous crust in the reference simulation is defined by a 'wet' quartzite dislocation creep flow law 
(Paterson and Luan 1990), but stronger rheologies were also tested, relying on quartz-diorite (Ranalli 1997) and felsic granulite (Wilks and Carter 1990) dislocation creep flow laws (Table 2).

For the isotropic part of the mantle rheology, we used a traditional dislocation creep power law because exponential flow laws that better describe the mechanical behaviour of the shallowest lithospheric mantle (Boioli et al. 2015; Gouriet et al. 2019) have more complex formulations, which hinder their coupling with our parameterized description of the viscous anisotropy. A 'wet' dunite dislocation creep flow law (Chopra and Paterson 1981) defines the reference mantle rheology. Although data in natural peridotites indicate that olivine in the shallow lithospheric mantle has low $\mathrm{H}^{+}$contents (Demouchy and Bolfan-Casanova 2016), this flow law was chosen because it predicts moderate deviatoric stresses in the shallowest mantle $\left(<500 \mathrm{MPa}\right.$ at strain rate of $\left.10^{-15} \mathrm{~s}^{-1}\right)$, which is consistent with low-temperature experimental data on olivine polycrystals (Demouchy et al. 2014) and predictions of dislocation dynamics models (Boioli et al. 2015; Gouriet et al. 2019). To test the effect of the isotropic part of the mantle rheology on the strain distribution, simulations were also performed for a weaker 'wet' (Hirth and Kohlstedt 2003) and a stronger 'dry' dunite (Chopra and Paterson 1984) dislocation creep flow laws. Material parameters for all cases are summarized in Table 2.

A small finite strain is imposed to test whether the fossil anisotropy in the mantle may produce strain localization in the entire lithospheric column and to quantify the initial stages of this process before it is modified by the evolution of the microstructure. For finite strains $<10 \%$, the evolution of the olivine CPO is negligible (Tommasi et al. 2000; Boneh et al. 2015; Thieme et al. 2018). The olivine CPO and associated viscous anisotropy (calibrated Hill parameters) in the two mantle domains are therefore maintained constant throughout the simulations. The olivine CPO in the mantle shear zone has maximum concentration of [100]axes parallel to the fossil shear direction and [010]-axes normal to the fossil shear plane, while [001]-axes lies vertically (Figure 1 and 2). This orthorhombic CPO is representative of 'wrench-fault type' mantle fabric, consistent with seismic anisotropy measurements in largescale strike-slip shear zones (e.g., Vauchez and Nicolas 1991; Hearn et al. 1996; Tommasi et al. 1999; Baldock and Stern 2005, Vauchez et al. 2012). The weak $(\mathrm{J}=2.8)$ and strong $(\mathrm{J}=12.7) \mathrm{CPO}$ used in the present simulations are representative of the range of olivine CPO intensities measured in naturally deformed peridotites (Tommasi and Vauchez 2015). 


\section{Results}

\section{Impact of the mantle shear zone orientation and CPO intensity}

Strain localization in the fossil mantle shear zone, quantified by the contrast in the $2^{\text {nd }}$ invariant of the viscoplastic strain rate $J_{2}\left(\mathbf{D}_{v}\right)=\left(\frac{3}{2} \mathbf{D}_{v}: \mathbf{D}_{v}\right)^{1 / 2}$ between the fossil mantle shear zone and the surrounding mantle, is only observed between $35^{\circ}<\theta<55^{\circ}$ (Figure 3a). At these loading-geometries, strain localization in the mantle is transmitted to the crust, as indicated by the contrast in strain rate between the crust directly above the reactivated mantle shear zone and the surrounding crust (Figure 3b). Strain localization in the mantle and crust varies non-linearly with the orientation of the fossil mantle shear zone. There is a marked reduction in strain localization between $\theta=45^{\circ}$ and $\theta=40^{\circ}$ or $\theta=50^{\circ}$. The mantle within and the crust atop a fossil shear zone trending normal to the imposed shortening $\left(\theta=90^{\circ}\right)$ show lower strain rates than the surrounding isotropic mantle and crust, respectively. Finally, fossil shear zones oriented at $30^{\circ}$ or between $55^{\circ}$ and $75^{\circ}$ to the imposed shortening are neutral; they produce neither significant strain localization nor delocalization.

The maximum strain localization occurs for the $\theta=45^{\circ}$ loading-geometry, because in this configuration the maximum concentrations of both [100]- and [010]-axes of the olivine $\mathrm{CPO}$ in the fossil shear zone are at $45^{\circ}$ to the imposed horizontal shortening (cf. pole figures in Figure 3). This leads to high shear stresses resolved on the easy (010)[100] slip system for most olivine crystals within the mantle shear zone. At the $\theta=90^{\circ}$ loading-geometry, strain rates are low within the mantle shear zone because the maximum concentrations of [100]- and [010]-axes are perpendicular and parallel to the imposed shortening, respectively, resulting in low resolved stresses on the three main slip systems of olivine for most crystals. The reactivation of the fossil mantle shear zone induces the development of faults and shear zones in the crust atop it, but strain localization in the crust is lower than in the mantle (Figure 3a,b). In simulations for the $\theta=45^{\circ}$ loading-geometry with the strong olivine $\mathrm{CPO}$, the crust atop the fossil mantle shear zone deforms on average $\sim 10$ times faster than the surrounding crust, whereas strain rates in the reactivated mantle shear zone are on average $\sim 30$ times faster than in the surrounding mantle. The contrast in magnitude of strain localization between the mantle and the crust is reduced when the strength of the CPO within the mantle shear zone is weaker. Strain rates are enhanced by a factor $\sim 3$ in the mantle shear zone and $\sim 2$ in the crust atop it relative to their surroundings (Figure 3a,b). The vertical strain distribution in the crust atop the shear zone also differs as a function of the CPO intensity in the fossil mantle shear 
zone (Figure 3b). In simulations with a strong CPO, the strain rate in the lower crust atop the mantle shear zone is considerably higher than in the upper crust. In simulations with a weak $\mathrm{CPO}$, the strain rate is more homogenously distributed with depth.
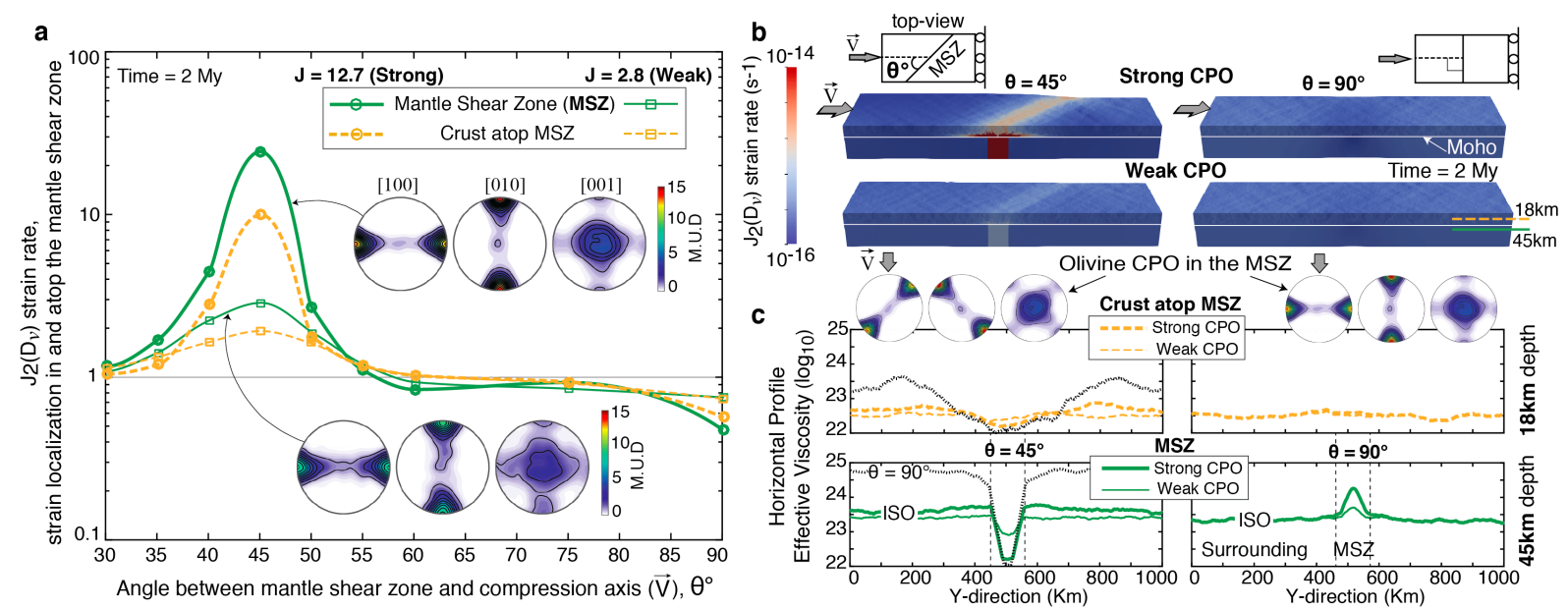

Figure 3: a) Strain localization at steady-state ( $\sim 2 \mathrm{My})$ as a function of the orientation of the fossil mantle shear zone relative to the imposed shortening ( $\theta$, loading-geometry). The strain localization is quantified by the ratio between the average of the $2^{\text {nd }}$ invariant of the strain rate $J_{2}\left(\mathrm{D}_{v}\right)$ in the fossil mantle shear zone (MSZ: green full lines) or in the crust right above it (yellow dashed lines) relatively to the surrounding upper mantle or crust, respectively. Simulations were performed for either strong $(\mathrm{J}=12.7$, thick lines) or weak olivine CPO $(\mathrm{J}=$ 2.8, thin lines) in the fossil mantle shear zone. (b) Strain rate field at steady-state in simulations with two different orientations of the fossil strike-slip mantle shear zone relative to the imposed shortening $\left(\theta=45^{\circ}\right.$ or $\left.90^{\circ}\right)$, in which either the strong or the weak olivine $\mathrm{CPO}$ was ascribed to the mantle shear zone. Pole figures illustrate the orientation-relation between the olivine CPO in the fossil mantle shear zone and the imposed shortening. (c) Horizontal effective viscosity profiles at $18 \mathrm{~km}$ (middle crust) and $45 \mathrm{~km}$ depth (uppermost mantle) for the four simulations shown in $(b)$. Black thin dashed lines in $(c)$ are the mantle and crust effective viscosity profiles for the relation between $\mathrm{CPO}$ in the mantle shear zone and surrounding upper mantle that results in the maximum contrast in mechanical behavior (i.e., [100]-axes at $45^{\circ}$ and $90^{\circ}$ to the compression direction, respectively). Pole figures are contoured at one multiple of a uniform distribution interval.

The variation in strength between the different domains may be quantified by comparing their effective viscosities, calculated as $\eta=J_{2}(\mathbf{S}) / 2 J_{2}\left(\mathbf{D}_{v}\right)$. Figure $3 \mathbf{c}$ shows the effective viscosity along horizontal profiles parallel to the Y-axis (external reference frame $\mathrm{XYZ}$ ) in the central part of the modelled domain at $18 \mathrm{~km}$ depth (ductile crust) and $45 \mathrm{~km}$ depth (shallow lithospheric mantle). Deformation of a plate with a fossil mantle shear zone with a strong $\mathrm{CPO}$ in the $\theta=45^{\circ}$ loading-geometry induces effective viscosities within the mantle shear zone $\sim 30$ times lower than in the surrounding mantle, whereas the middle crust atop the fossil shear zone has an effective viscosity $<5$ times lower than the surrounding crust. At the $\theta=90^{\circ}$ loading-geometry, a mantle shear zone with a strong CPO displays 
effective viscosities $\sim 5$ times higher than the surrounding mantle. In this simulation the lateral contrast in effective viscosity in the middle crust is negligible. For cases with a weak CPO in the fossil mantle shear zone and an isotropic surrounding mantle, the effective viscosity contrast between the mantle shear zone and the surrounding mantle is reduced to $<3$ times for both $\theta=45^{\circ}$ and $\theta=90^{\circ}$ loading-geometries. The contrast is even lower in the crust, being only detectable for the $\theta=45^{\circ}$ loading-geometry (Figure 3c).

The contrast in effective viscosity is significantly enhanced if the surrounding upper mantle has a non-random olivine CPO with maximum concentrations of [100]- and [010]axes oriented perpendicular and parallel to the compression direction, respectively (i.e., equivalent to the $\mathrm{CPO}$ in the shear zone at $\theta=90^{\circ}$ ). For a strong CPO in both the mantle shear zone at $\theta=45^{\circ}$ and the surrounding mantle with the orientation described above, the effective viscosity contrast reaches factors $\sim 500$ in the mantle and $\sim 30$ in the crust (black dashed lines in Figure 3c). This is mainly due to the strain rates in the fossil mantle shear zone and in the crust right above, which are a factor $\sim 200$ and $\sim 100$ higher than in the surrounding mantle and crust, respectively (Supplementary material Figure S2).

The mechanical response of the mantle shear zone is not perfectly symmetric regarding complementary loading-geometries, e.g., strain localization is slightly more effective for $\theta=40^{\circ}$ than for $\theta=50^{\circ}$ (Figure 3a). This small asymmetry results from the difference in critical resolved shear stresses (relative strength) between the (001)[100] and (010)[001] slip systems in olivine (Table 1). For orientations of the fossil mantle shear zone lying at $50^{\circ} \leq \theta \leq 90^{\circ}$ to the applied stress, the hard (010)[001] slip system accommodates more deformation than the easy (001)[100] slip system. For a fossil mantle shear zone oriented at $0^{\circ} \leq \theta \leq 40^{\circ}$ the easy slip system (001)[100] is more active than (010)[001], which results in slightly more effective strain localization.

\section{Influence of imposing different lateral boundary conditions}

In the previous simulations, lithospheric pressure conditions (P-litho) were applied to the lateral boundaries of the model (Figure 2). In the present section, we investigate the effect of imposing free-slip boundary conditions (F-slip) to these boundaries. In F-slip conditions, the strain localization in the fossil mantle shear zone occurs for a more limited range of loading-geometries and the magnitude of the localization is considerably reduced (Figure 4a). For a fossil mantle shear zone oriented at $45^{\circ}$ to the imposed shortening, the contrast in strain rate relatively to the surrounding mantle is reduced from a factor $\sim 30$ in P-litho to a factor $\sim 2$ in F-slip conditions. In the latter, the weaker strain localization in the fossil mantle 
shear zone does not promote strain localization in the crust atop it. Therefore, the deformation in the crust differs considerably from the one in a simulation with the same orientation of the fossil shear zone but with P-litho conditions at the lateral boundaries. In F-slip conditions evenly spaced faults oriented normal to the applied shortening develop across the entire crust, regardless the loading-geometry.

Analysis of the different components of the strain rate in the mantle shear zone $\left(D_{i j}\right)$ as a function of loading-geometry indicates that the change in the lateral boundary conditions affects essentially shearing parallel to the mantle shear plane - the component parallel to the maximum [100]-axes of the olivine CPO (Figure 4b). When P-litho conditions are imposed to the lateral boundaries, if the mantle shear zone is oriented at $45^{\circ}$ to an imposed horizontal shortening, shearing parallel to the fossil shear plane $\left(\mathrm{D}_{x^{\prime} y^{\prime}}\right)$ dominates the deformation. F-slip conditions on the lateral boundaries hinder this shearing component, which is $\sim 8$ times slower than under the P-litho conditions. The variation of the components $\mathrm{D}_{x^{\prime} x^{\prime}}, \mathrm{D}_{y^{\prime} y^{\prime}}$ and $\mathrm{D}_{z^{\prime} z^{\prime}}$ between the two sets of boundary conditions is much smaller. For both P-litho and F-slip lateral boundary conditions, a fossil mantle shear zone is reactivated in transpression when oriented at $40^{\circ}-50^{\circ}$ to an imposed horizontal shortening. However, the vorticities are markedly different. In F-slip conditions, shortening normal to the fossil shear zone trend is equivalent to along-strike shearing, whereas in P-litho along-strike shearing largely predominates.

For both F-slip and P-litho lateral boundary conditions, the deformation with loadinggeometries $\theta<45^{\circ}$ are characterized by higher $\mathrm{D}_{x^{\prime} x}$, than $\mathrm{D}_{y^{\prime} y^{\prime}}$ strain rates components. The opposite behaviour is observed for loading-geometries $\theta>45^{\circ}$. The $\mathrm{D}_{z^{\prime} z^{\prime}}$ component remains constant and positive (indicating thickening parallel to $Z$ ) independent of loading-geometry and boundary conditions. At $\theta>45^{\circ}$ loading-geometries, the $\mathrm{D}_{y^{\prime} y^{\prime}}$ components are negative (indicating shortening parallel to $Y^{\prime}$ ) for both sets of lateral boundary conditions, but the $\mathrm{D}_{x^{\prime} x^{\prime}}$ component are almost null under F-slip conditions and positive under P-litho conditions. At $\theta<45^{\circ}$ loading-geometries, $\mathrm{D}_{x^{\prime} x}$, components are negative, whereas $\mathrm{D}_{y^{\prime} y^{\prime}}$ components are almost null under F-slip conditions, but positive under P-litho conditions. This implies an unexpected, but small, widening of the mantle shear zone despite the imposed large-scale shortening. This widening does not occur in F-slip conditions, indicating that it is a direct consequence of the full (3D) expression of the olivine viscous anisotropy when the plate is deformed at P-litho conditions. 

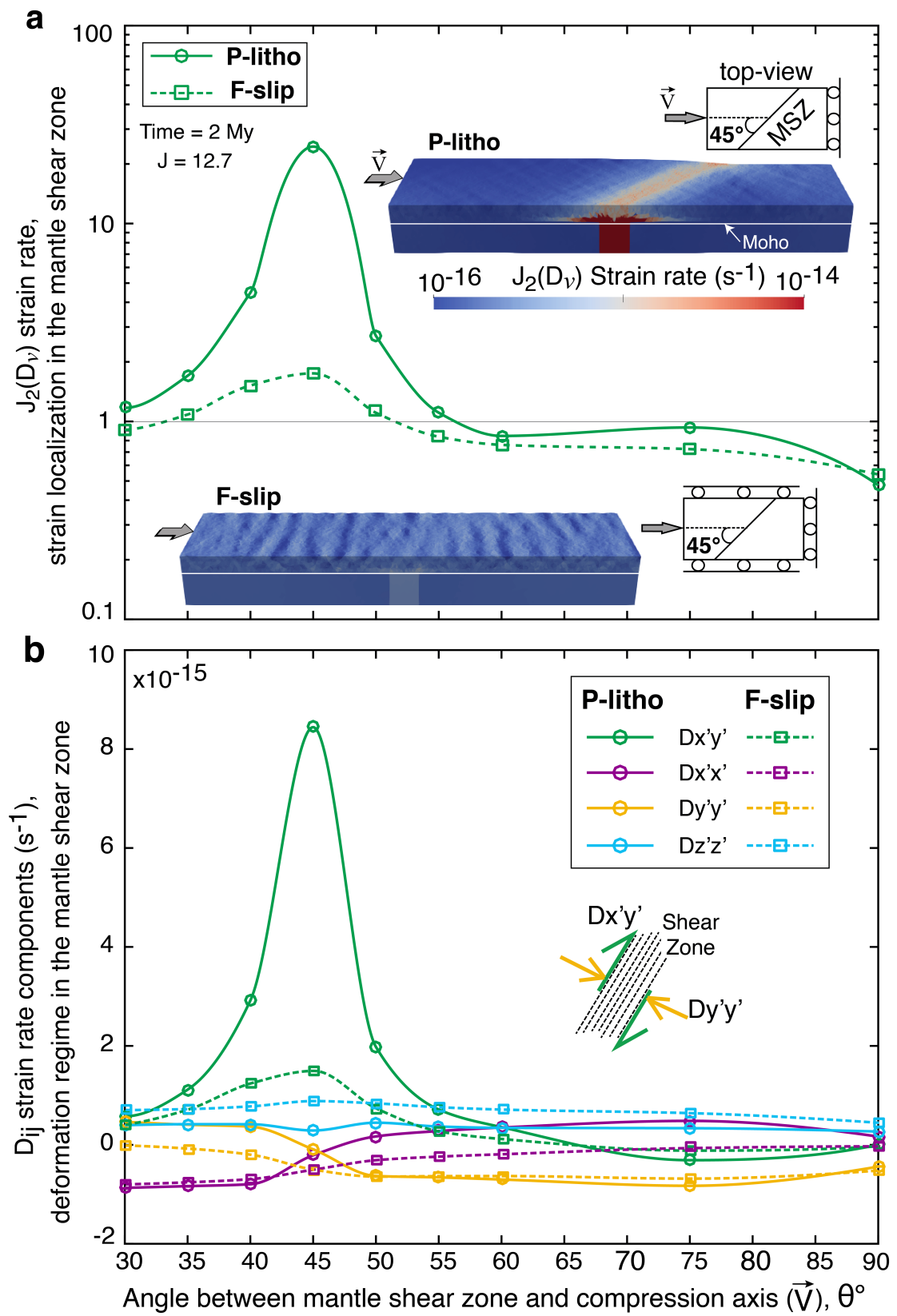

Figure 4: Effect of varying the conditions imposed on the lateral boundaries from lithostatic pressure (P-litho, full lines) to free-slip (F-slip, dashed lines) on (a) the strain localization, quantified by the ratio between the average of the $2^{\text {nd }}$ invariant of the strain rate $J_{2}\left(\mathrm{D}_{v}\right)$ in the fossil strike-slip mantle shear zone and in the surrounding upper mantle, and on (b) deformation regime in the mantle shear zone, characterized by the components of the strain rate $\left(\mathrm{D}_{\mathrm{ij}}\right)$ plotted in the mantle shear zone reference frame (X'Y'Z') as a function of the loading-geometry $(\theta)$. Predictions at steady-state conditions $(\sim 2 \mathrm{My})$ for simulations with a strong olivine CPO in the mantle shear zone. Inserts in $(a)$ show the $2^{\text {nd }}$ invariant of the strain rate field for the reference loading-geometry $\left(\theta=45^{\circ}\right)$ obtained using both boundary conditions.

\section{Anisotropy versus isotropic viscous weakening in the mantle shear zone}

Does the effect of heterogeneity in viscous anisotropy (due to a lateral variation in olivine CPO) within the upper mantle differ from the effect of an isotropic rheological 
heterogeneity (due to a lateral variation in temperature, composition, grain size...) with the same geometry and orientation relative to the imposed loading? To answer this question, we ran simulations with a fossil strike-slip mantle shear zone with a random olivine CPO, but an $a d-h o c$ increase in the fluidity $\gamma$ (Eq.4; Table 5.2) by a factor 10 or 100 relative to the surrounding mantle. At constant stress, an increase in the fluidity results in an increase in strain rate by the same factor.

\begin{tabular}{|c|c|c|c|c|c|c|}
\hline & $\begin{array}{c}\text { Wet } \\
\text { Quartzite }^{\mathrm{a}}\end{array}$ & $\begin{array}{l}\text { Quartz- } \\
\text { Diorite }^{b}\end{array}$ & $\begin{array}{c}\text { Felsic } \\
\text { Granulite }^{c}\end{array}$ & $\begin{array}{c}\text { Dry } \\
\text { Dunite }^{d}\end{array}$ & $\begin{array}{l}\text { Wet } \\
\text { Dunite }\end{array}$ & $\begin{array}{c}\text { Wet } \\
\text { Dunite }^{\mathrm{f}}\end{array}$ \\
\hline Density $\left(\mathrm{kg} \mathrm{m}^{-3}\right) \rho$ & $2.65 \mathrm{e} 3$ & $2.65 \mathrm{e} 3$ & $2.7 \mathrm{e} 3$ & $3.3 \mathrm{e} 3$ & $3.3 \mathrm{e} 3$ & $3.3 \mathrm{e} 3$ \\
\hline Young modulus (GPa) & 70 & 70 & 70 & 160 & 160 & 160 \\
\hline Poisson ratio & 0.25 & 0.25 & 0.25 & 0.28 & 0.28 & 0.28 \\
\hline Fluidity $\left(\mathbf{P a}^{-\mathbf{n}} \mathbf{s}^{-1}\right) \gamma$ & $1.63 e-26$ & $1.14 \mathrm{e}-28$ & 4.e-25 & $2.42 \mathrm{e}-16$ & $3.98 \mathrm{e}-25$ & $3.56 \mathrm{e}-16$ \\
\hline Activation energy $\left(\mathrm{kJmol}^{-1} \mathbf{K}^{-1}\right) Q$ & 135 & 123 & 260 & 545 & 498 & 480 \\
\hline Stress exponent $n$ & 3.1 & 3.2 & 3.4 & 3.5 & 4.5 & 3.5 \\
\hline Angle of friction* $\phi$ & 30 & 30 & 30 & - & - & - \\
\hline Cohesion (MPa) $c$ & 10 & 10 & 10 & - & - & - \\
\hline
\end{tabular}

Reactivation of the isotropic rheological heterogeneity within the upper mantle occurs for all loading-geometries (Figure 5a). The magnitude of strain localization also depends on the orientation of the isotropic heterogeneity relative to the imposed loading, but in a weaker manner than for an anisotropic (olivine CPO-controlled) heterogeneity. Similarly to the anisotropic mantle shear zone, the maximum strain localization occurs when the maximum elongation of the tabular isotropic heterogeneity is at $\theta=45^{\circ}$ to the imposed shortening, but strain rates for this orientation are only $\sim 10$ times higher than for the $\theta=90^{\circ}$ loadinggeometry. For comparison, the strain rate contrast between the two loading geometries in CPO-induced anisotropic models attains a factor $\sim 60$. This may be explained as variations in the mechanical behaviour of the isotropic heterogeneity as a function of its orientation result only from its tabular shape, i.e., from high resolved shear stress projected onto the elongation of the heterogeneity.-The anisotropic mantle shear zone presents a more non-linear variation in strain localization as a function of the loading-geometry than the isotropic one (Figure 5a). At the $\theta=45^{\circ}$ loading-geometry, the strain localization in the anisotropic mantle shear zone is similar to the one observed in an isotropic mantle shear zone 100 times weaker than the surrounding mantle (fluidity increased by a factor 100). For $\theta=40^{\circ}$ or $50^{\circ}$ loadinggeometries, an increase in the fluidity of the isotropic fossil shear zone by a factor $\sim 10$ better approximates the response of the anisotropic fossil mantle shear zone. For loading-geometries between $60^{\circ} \leq \theta \leq 90^{\circ}$, strain still weakly localizes in the isotropic fossil mantle shear zone, 
whereas the anisotropic one displays a factor $<3$ lower strain rates than the surrounding mantle.
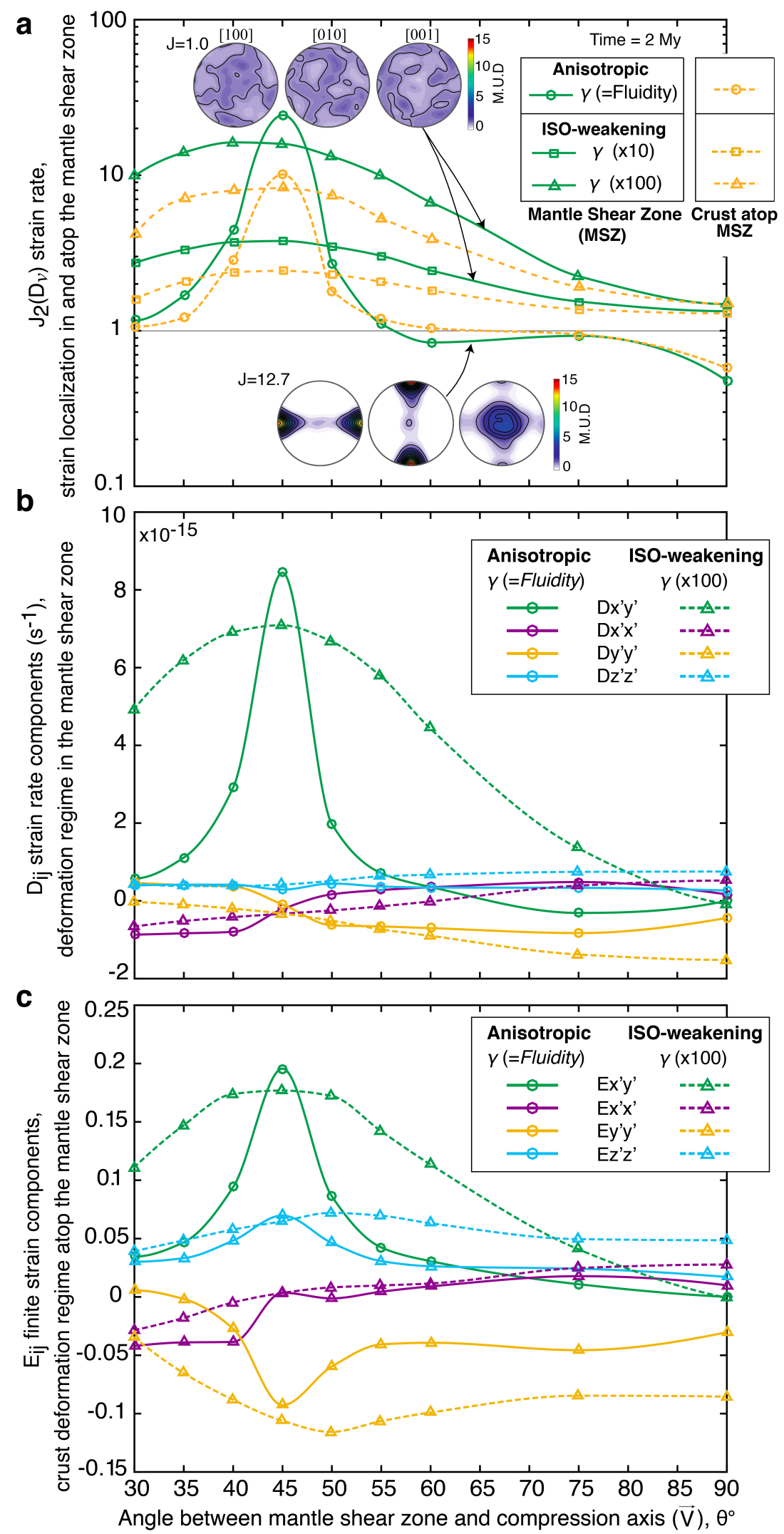

(caption in next page) 
Figure 5: (a) Comparison between the strain localization at steady-state ( 2My) in a fossil mantle shear zone with either a strong olivine CPO (anisotropic; J-index $=12.7$ ) or a random olivine CPO (isotropic; J-index $=1.0$ ) but a 10- or 100-fold increase in the fluidity ( $\gamma$ in Eq. 3 and 4 and Table 2) for different orientations of the fossil mantle shear zone relative to the imposed shortening direction. Strain localization is quantified by the ratio between the average of the $2^{\text {nd }}$ invariant of the strain rate $J_{2}\left(\mathrm{D}_{v}\right)$ within the mantle shear zone (green full lines) or in the crust right above it (yellow dashed lines) and the same quantity in the surrounding upper mantle or crust, respectively. (b) Deformation regime in the mantle shear zone, characterized by the components of the average strain rate $\left(D_{i j}\right)$ in the shear zone reference frame ( $X^{\prime} Y^{\prime} Z^{\prime}$ ) as function of the loading-geometry for both anisotropic and isotropic (100-fold increase in the fluidity) simulations. (c) Deformation regime in the crust just atop the fossil mantle shear zone characterized by the components of the average finite strain $\left(E_{i j}\right)$ in the shear zone reference frame ( $\left.X^{\prime} Y^{\prime} Z^{\prime}\right)$.

Comparison of the components of the strain rate at steady-state as function of loadinggeometry corroborates that in both isotropic and anisotropic cases structural reactivation of a

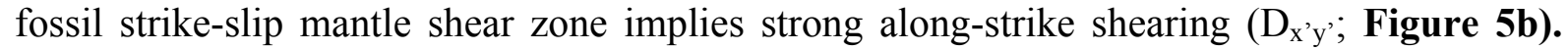
However, the magnitude of $\mathrm{D}_{x^{\prime} y^{\prime}}$ component as a function of the loading-geometry differs significantly between the isotropic and anisotropic cases. At the $\theta=45^{\circ}$ loading-geometry, $\mathrm{D}_{\mathrm{x}}{ }^{\prime} \mathrm{y}$, strain rates in the anisotropic fossil mantle shear zone are higher than in the isotropic fossil shear zone with a factor 100 increase in fluidity. For all other oblique loadinggeometries, the magnitude of the $\mathrm{D}_{\mathrm{x}^{\prime} \mathrm{y}}$ 'component is significantly higher in the isotropic than in the anisotropic fossil mantle shear zone.

The inversion between the $\mathrm{D}_{y^{\prime} y^{\prime}}$ and $\mathrm{D}_{x^{\prime} x^{\prime}}$ components in the mantle shear zone for shortening at angles lower or higher than $45^{\circ}$ relative to the fossil shear zone trend also occurs in the isotropic case, indicating that this inversion is due to macroscopic geometrical reasons rather than an effect of the CPO-induced viscous anisotropy. In contrast, widening of the mantle shear zone (positive $\mathrm{D}_{y^{\prime} y^{\prime}}$ ) for loading-geometries between $30^{\circ} \leq \theta \leq 45^{\circ}$ does not occur in the case with isotropic rheological heterogeneity (Figure 5b). Therefore, (1) the widening of the fossil strike-slip mantle shear zone despite the imposed shortening, (2) the asymmetry of the mechanical response relative to complementary loading-geometries, and (3) the strong non-linearity of the strain localization pattern as a function of the loading-geometry are direct consequences of the CPO-induced viscous anisotropy within the fossil mantle shear zone.

Analysis of the components of the finite strain $\left(E_{i j}\right)$ averaged over depth in the crust atop the fossil mantle shear zone shows that the deformation regime in the crust follows the deformation regime developed in the mantle (Figure 5c). The $\theta=45^{\circ}$ loading-geometry is characterized by high transpressional strains in the crust for both isotropic and 
anisotropic cases, but vorticity $\left(\mathrm{E}_{\left.\mathrm{x}^{\prime} \mathrm{y}^{\prime}\right)}\right)$ is lower than in the mantle shear zone. In the isotropic case, transpression in the crust is observed for all loading-geometries between $30^{\circ} \leq \theta \leq$ $80^{\circ}$, although strain magnitude decreases with decreasing obliquity of the heterogeneity. In the anisotropic case, the along-strike strain component $E_{x^{\prime}}{ }^{\prime}$ in the crust is only important for loading-geometries $35^{\circ} \leq \theta \leq 55^{\circ}$.

\section{Interactions between strain localization in the upper mantle and in the brittle crust}

To analyse possible feedbacks between strain localization in the viscous mantle and in the brittle crust, we ran simulations in which frictional weakening is applied by reducing the initial static angle of friction $\phi_{0}$ in the mesh element of the crust fault from $30^{\circ}$ to $\phi_{f}=$ $15^{\circ}, 10^{\circ}$, or $5^{\circ}$ after $1 \%$ of plastic strain and keeping it thereafter constant. The reduction in the angle of friction lowers locally the resistance of the rocks to further deformation by brittle processes (Eq.2), allowing long-lived faults to form in the upper crust.

The strain localization in the fossil strike-slip mantle shear zone and in the crust in the reference loading-geometry $\left(\theta=45^{\circ}\right)$ increases with increasing frictional weakening, as illustrated by the $2^{\text {nd }}$ invariant of the finite strain field $J_{2}(\mathbf{E})=\left(\frac{3}{2} \mathbf{E}: \mathbf{E}\right)^{1 / 2}$ in Figure 6a. In absence of frictional weakening $\left(\phi_{0}=\phi_{f}=30^{\circ}\right)$, the upper crust remains homogeneously strong. The evolution of the strain localization with time is similar to that observed in simulations with the same geometry and CPO, but without a crustal layer (black dotted line in Figure 6b). However, the magnitude of strain localization is significantly reduced. When frictional weakening is active, the crustal faults, once formed, become weaker than the surroundings. This results in long-lived discrete faults forming an anastomosed network in the upper crust right atop the fossil mantle shear zone (Figure 6a). Strain localization in the upper crust results in further strain localization in the fossil mantle shear zone below, which in turn produces more strain localization in the crust right above it. The vertical distribution of strain in the crust also depends on the frictional weakening. In simulations with no frictional weakening, there is a marked variation of the strain distribution in the crust with depth (Figure 6a). In such cases, strain localization is weak in the middle and upper crust, and strong in the lowermost crust just atop the limits of the mantle shear zone. Strain in the lower crust is distributed in a diffuse zone with approximately twice the width of the fossil mantle shear zone. Frictional weakening results in a more homogeneous depth distribution of strain and stronger strain localization in the upper crust. For $\phi_{\mathrm{f}}=5^{\circ}$, deformation in the 
upper crust is focused in a $\sim 30 \mathrm{~km}$ wide network of crust faults atop the central part of the 50 $\mathrm{km}$ wide fossil mantle shear zone.
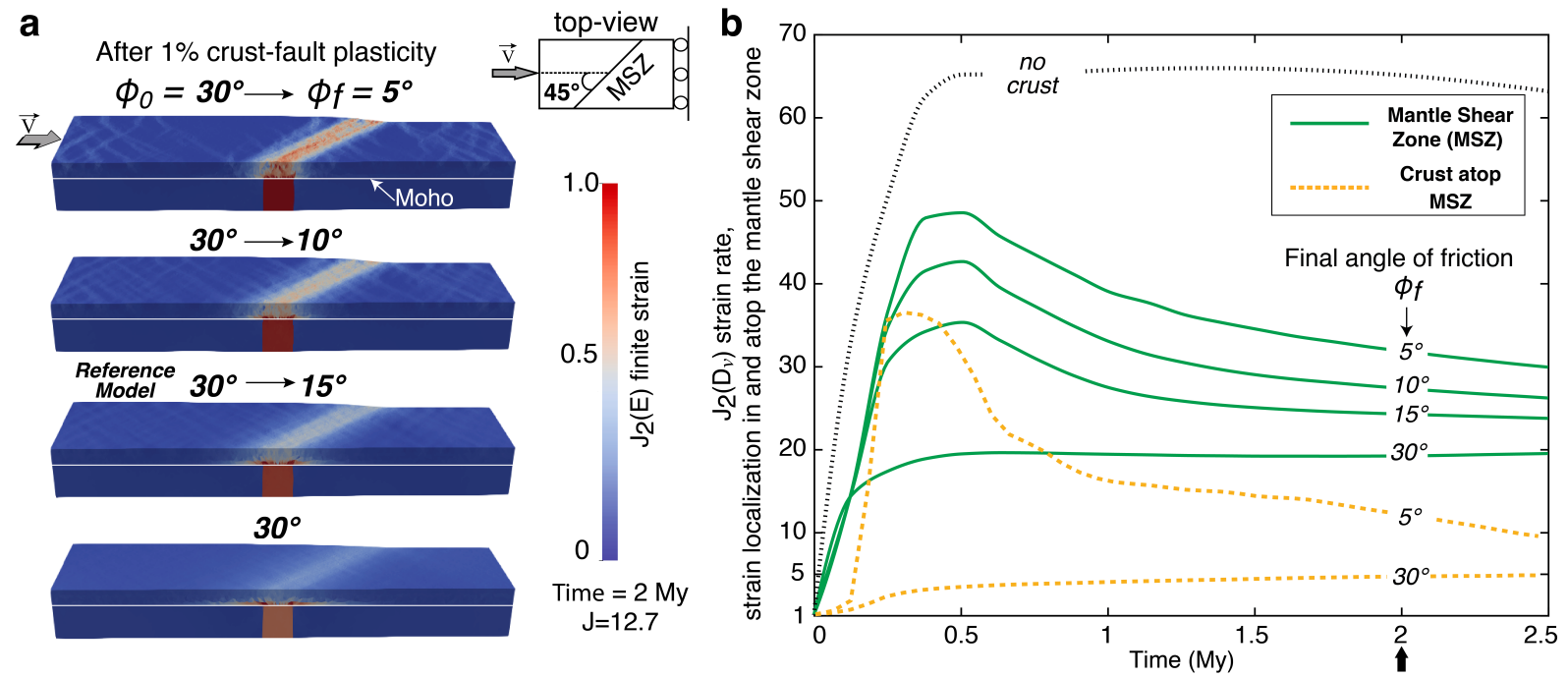

Figure 6: Feedbacks between frictional weakening in the brittle crust and strain localization due to viscous anisotropy in the fossil mantle shear zone. (a) Finite strain, $2^{\text {nd }}$ invariant $J_{2}(\mathrm{E})$ field, after 2 My of shortening for simulations with different final $\left(\phi_{\mathrm{f}}\right)$ angles of friction. (b) Evolution of the strain localization in the fossil mantle shear zone and in the crust above it, quantified by the ratio between the average of the $2^{\text {nd }}$ invariant of the strain rate $J_{2}\left(D_{v}\right)$ within the fossil mantle shear zone and at $10 \mathrm{~km}$-depth in the crust above it and the same quantities in the surrounding mantle and crust, as a function of time for the different simulations. All simulations were performed using a fossil shear zone oriented at $45^{\circ}$ to the imposed shortening and displaying a strong olivine CPO. The black arrow at $2 \mathrm{My}$ in $(b)$ indicates the time at which the finite strain fields presented in $(a)$ are extracted.

Feedbacks between strain localization in the brittle crust and mantle produce a timedependent behaviour (Figure 6b). If frictional weakening is not considered, i.e., $\phi_{f}=30^{\circ}$, average strain rates in the mantle shear zone are $\sim 20$ times faster than in the surrounding mantle and stay stationary over time. In contrast, when frictional weakening is imposed, the strain localization in the fossil mantle shear zone is initially enhanced by a factor proportional to the reduction in the angle of friction and decreases afterwards. Nevertheless, strain localization within the mantle shear zone with a given frictional weakening is at all times more effective than in a simulation with a weaker frictional weakening. The ratio between the average strain rate in the mantle shear zone and in the surrounding mantle is initially $\sim 33$ and decreases to $\sim 25$ in the simulation with $\phi_{f}=15^{\circ}$, whereas in a simulation with $\phi_{f}=5^{\circ}$ it is initially $\sim 50$ and decreases to $\sim 32$.

The evolution of strain localization in the crustal shear zone is similar to that in the fossil shear zone in the mantle (Figure 6b). For $\phi_{f}=5^{\circ}$, the peak of the average strain 
rate in the crust atop the fossil mantle shear zone is initially a factor $\sim 35$ faster than the surrounding crust and decreases to a factor $\sim 10$. For the case with $\phi_{f}=30^{\circ}$, the average strain rate in the crust atop the fossil mantle shear zone reaches a factor $\sim 5$ faster than the surrounding and remains fairly constant, as in the reactivated fossil mantle shear zone. The decrease in strain localization in the fossil mantle shear zone and crust in presence of frictional weakening results from the development, as the shortening proceeds, of faults in the upper crust outside the initial high strain domain right atop the mantle shear zone. Frictional weakening in these faults leads to reduction of the upper crust strength outside the crustal shear zone and to a more distributed deformation in the upper crust, which in turn, leads to less strain localization within the fossil mantle shear zone.

\section{Mechanical coupling between the ductile crust and upper mantle}

The results in the previous section highlight strong feedbacks between the mechanical behaviour and strain repartition in the lithosphere. To further investigate the effect of the mechanical coupling between crust and mantle on the strain localization, we varied the composition and hence the ductile strength of the crustal layer for a series of simulations with the fossil mantle shear zone oriented at $45^{\circ}$ to the imposed shortening and in which frictional weakening $\left(\phi_{f}=15^{\circ}\right)$ is imposed in the brittle upper crust.

We found that both the magnitude and the evolution of the strain localization depend on the rheology of the ductile crust (Figure 7a). Additionally, different behaviours are observed as a function of the strength contrast between the crust and mantle, which may be quantified as the ratio between the average effective viscosities in the two layers (Figure 7b). When the mantle is significantly stronger than the crust, e.g., dry dunite mantle and wet quartzite crust (red squares), strain localization in the mantle shear zone and in the crust atop it reaches a constant value without subsequent delocalization (similarly to the case with no frictional weakening in Figure 6b). This evolution, characterized by the absence of timedependent behaviour, is similar to one displayed by simulations without the crustal layer (dashed line in Figure 7a), but the presence of a strong crust results in weaker strain localization. A similar evolution, but even weaker strain localization, is predicted in simulations with a dry dunite mantle and two crustal layers, a wet quartzite upper crust and a felsic granulite lower crust (purple/red square), corroborating that increase in the lower crust strength results in decrease of normalized strain rates in the fossil mantle shear zone with a given (CPO) viscous anisotropy. High strength in the lower crust favours effective crust- 
mantle coupling and produces localized deformation in the entire crust right above the fossil shear zone. In contrast, simulations with a low strength lower crust display wider shear zones in the lower crust compared to the mantle shear zone, with the highest strain accumulated atop the limits of the mantle shear zone and much less strain localization in the upper crust (compare the inserts displaying the strain field in the coupled and decoupled cases in Figure $7 b)$.
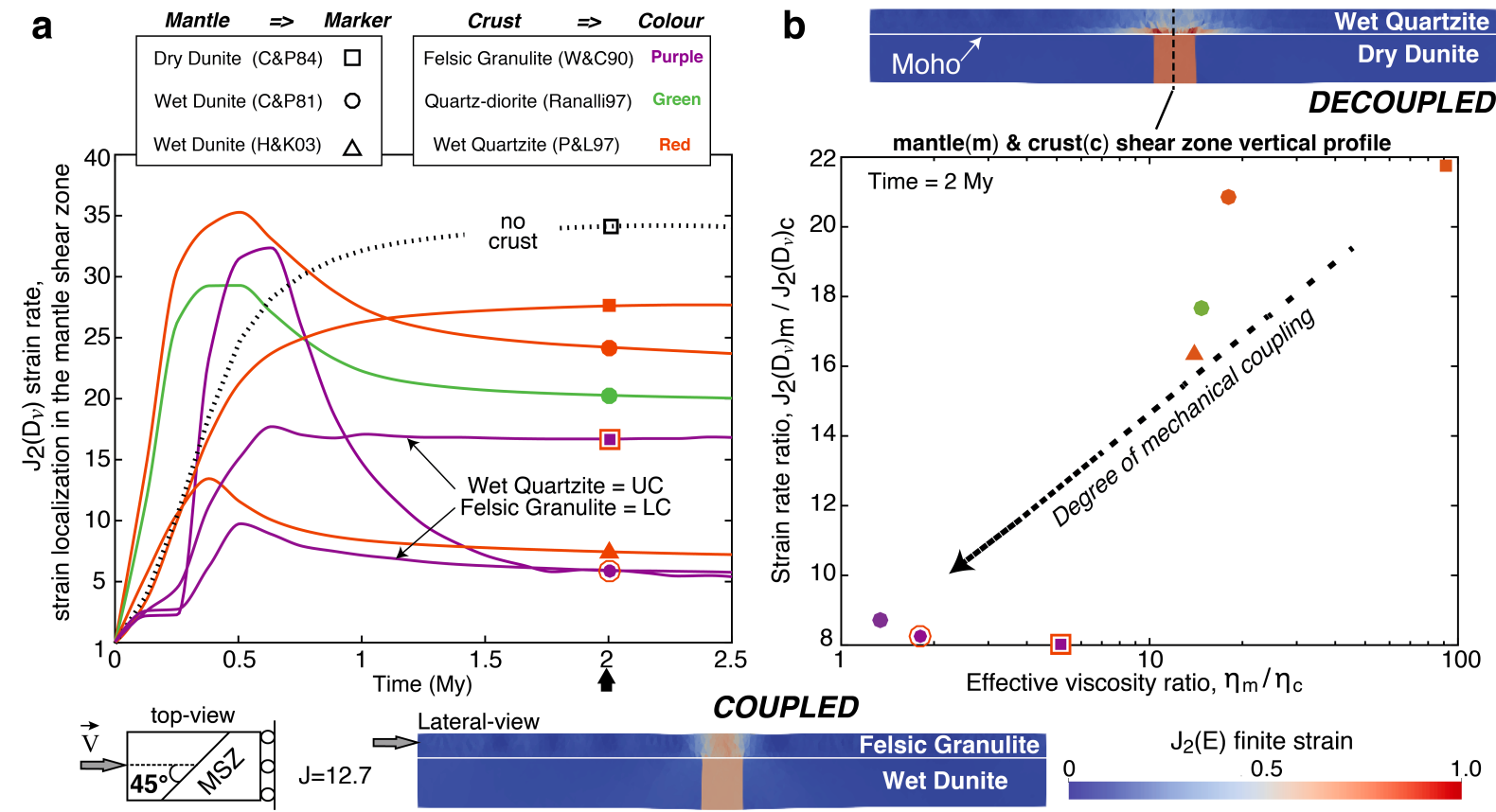

COUPLED

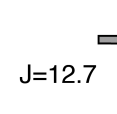

Lateral-view

Figure 7: (a) Evolution of the strain localization in the anisotropic fossil mantle shear zone as a function of time for simulations with different isotropic part of the mantle and crust rheologies, leading to different degrees of mechanical coupling between these layers. Strain localization is quantified by the ratio between the average of the $2^{\text {nd }}$ invariant of the strain rate $J_{2}\left(\mathrm{D}_{v}\right)$ within the fossil mantle shear zone and in the surrounding upper mantle. The colours indicate the crust rheology and markers the mantle rheology. Most simulations have a crust with a uniform composition, but two have a two-layer crust with a felsic granulite lower crust (LC) and a wet quartzite upper crust (UC). The black arrow indicates the time at which the results plotted in (b) are extracted. (b) Relation between the degree of mechanical coupling and the viscosity contrast between the mantle and the crust. The degree of mechanical coupling is quantified by the ratio between the average strain rate $J_{2}\left(\mathrm{D}_{v}\right)$ vertically integrated in the mantle shear zone and in the crust atop it. The ratio between effective viscosities $(\eta)$ in both domains is obtained by integrating the effective viscosity from the bottom of the mantle shear zone to the Moho and from the Moho to a depth of $25 \mathrm{~km}$ in the crust. The inserts show the strain field $\left(2^{\text {nd }}\right.$ invariant) after steady-state shortening for simulations displaying the highest (bottom) and lowest (above) degree of crust-mantle mechanical coupling. All simulations were performed using a fossil shear zone oriented at $45^{\circ}$ and displaying a strong olivine CPO. 
When the mantle is weak (wet dunite mantle: red, green and purple circles), strain localization is strongly time-dependent. After a peak at $\sim 0.5 \mathrm{My}$ of shortening, strain localization decreases over time and reaches steady-state at $\sim 2$ My ( $\sim 8 \%$ of bulk shortening). As in simulations with a strong dry mantle, the highest strain localization at steady-state occurs for the weakest crust (wet quartzite: red circle) and the lowest strain localization at steady-state, for the strongest crust (felsic granulite: purple circle). The highest peak strain localization is also observed for simulations with a weak ductile crust, whereas the lowest occurs when the upper crust is weak and the lower crust is strong (wet quartzite + felsic granulite: purple/red circle). The most vigorous decrease in strain localization as a function of time occurs in the simulation with the strongest ductile crust (felsic granulite: purple circle, from a factor $\sim 32$ to $\sim 7$ ). In this case, strain rates at steady-state are similar to that of the simulations with a two-layer crust where the lower crust have felsic granulite composition, suggesting that the lower crust rheology controls the steady-state deformation. Further reduction in the mantle strength (red triangle) results in less efficient strain localization in the entire lithosphere relative to simulations with a similar crust, but a stronger mantle (red circle) rheology. In summary, for a given isotropic mantle rheology, strain localization in the mantle shear zone (and in the crust) tends to decrease with increasing crustal strength, and for a given lower crust rheology, strain localization tends to increase with increasing mantle strength.

The degree of mechanical coupling between the crust and mantle for the different simulations was estimated using the ratio of the depth-integrated $2^{\text {nd }}$ invariant of the strain rate in the mantle shear zone and in the crust right atop it. Comparison of this coupling measure with the mantle-crust strength contrast, characterized as the ratio of the depthintegrated effective viscosities in both domains $\left(\eta_{m} / \eta_{c}\right.$; Figure $\left.7 \mathbf{b}\right)$, confirms that at first order, the higher the strength contrast, the lower the degree of mechanical coupling. Two endmembers were recognized in the simulations. The most decoupled case has a weak wet quartzite crust and a strong dry dunite mantle. The most coupled case has a strong felsic granulite crust and a weak wet dunite mantle. When mantle and crust are decoupled, strain localization is highly variable as a function of depth, being strong in the mantle and in the lowermost crust, but weak in the middle and upper crust (cf. upper inset in Figure $\mathbf{7 b}$ ). Conversely, when the mantle and crust are coupled, strain localization is more homogeneously distributed as a function of depth and strain localizes in a narrower domain in the crust, which width is equal or lower than the width of the fossil mantle shear zone (cf. lower inset in Figure 7b). 


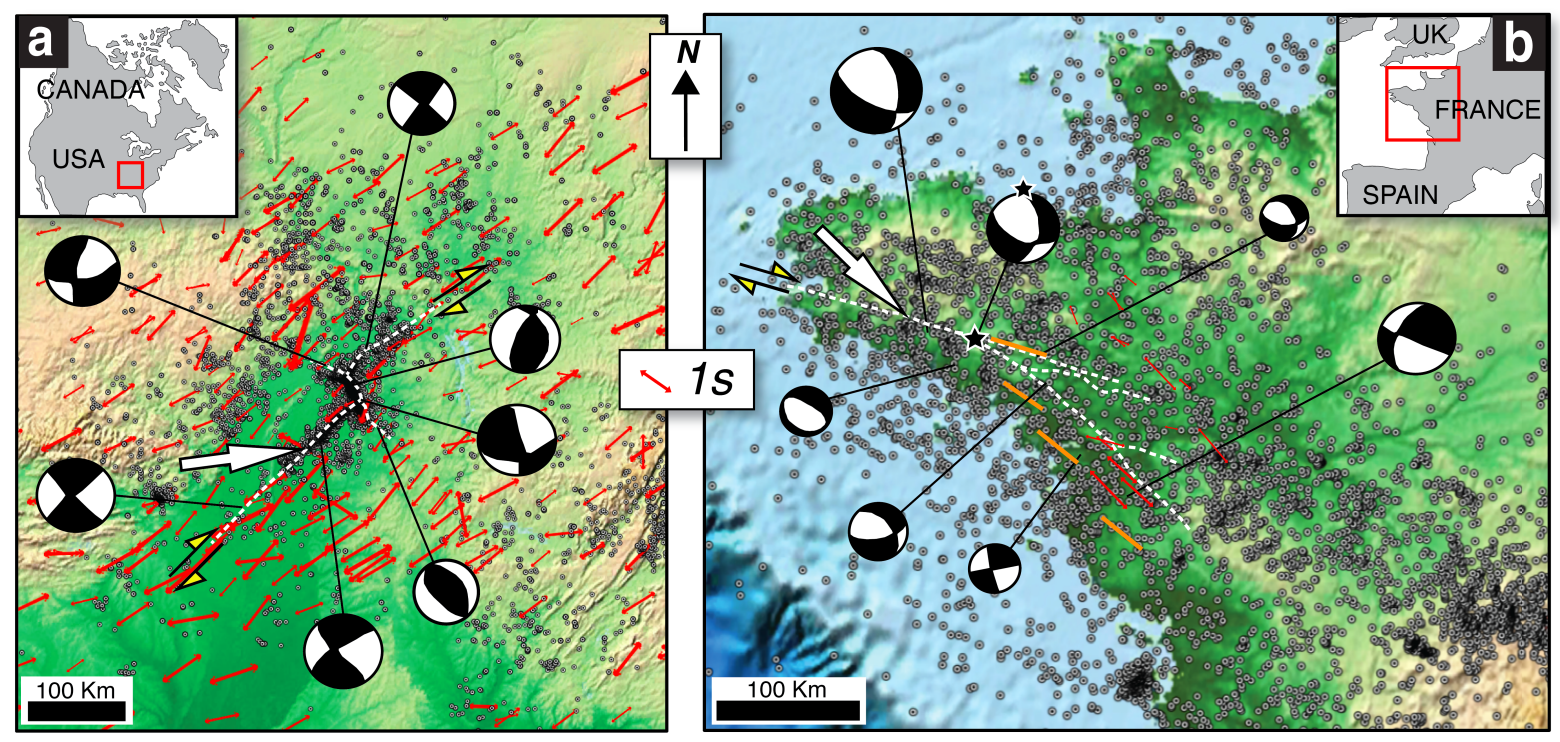

Fast SKS polarization

Fast Pn propagation

Figure 8: Orientation-relation between present-day principal horizontal stresses (large white arrow: compressional) and the horizontal projection of the dominant orientation of olivine [100]-axes (mantle fabric, inferred as parallel to the direction of fast polarization of S-waves or propagation of Pn-waves) in the (a) New Madrid (NM) and (b) South Armorican (SA) seismic zones. The horizontal stress direction and the focal mechanisms in the NM and SA seismic zones are based on Johnson et al. (2014) and Mazabraud et al. (2004). In the NM zone the focal mechanisms are characterized mainly by strike-slip solutions and in the SA mainly by oblique solutions. Seismic anisotropy measurements were derived from the shearwave splitting database (splitting.gm.univ-montp2.fr/DB/; Barruol et al. 2009). Most SKS splitting data in the NM zone are from Nyamwandha and Powell (2016). Pn anisotropy in the SA zone is from Judenherc (2000) and SKS splitting data are from Judenherc (2003). Earthquakes locations in the NM and SA seismic zones are derived from the United States Geological Survey (USGS; earthquake.usgs.gov) and from the SHARE European Earthquake Catalogue (SHEEC; Grünthal at el. 2013; Stucchi et al. 2013). The black star in (b) indicate the location of the $\mathrm{Mw}=4.3$ Lorient event (Perrot et al. 2005).

An integrated analysis of the results presented in the Figure $7 \mathbf{a}, \mathbf{b}$ indicates that the mechanically coupled and decoupled end-members display the maximum and minimum amount of strain localization at steady-state, respectively. In the coupled case, strain localization in the fossil mantle shear zone is initially high, but decreases significantly over time. In the decoupled case, strain localization is initially lower, but once it attains a maximum value, it remains constant. This difference in the evolution of strain localization over time arises from a higher influence of the strain repartition in the crust when the latter is mechanically strong. Thus, a relatively strong crust has a three-fold effect in the deformation of the lithosphere: (1) it better transmits stresses from the mantle, resulting in a stronger initial 
strain localization and a more homogeneous depth distribution of strain in the crust, (2) it increases the resistance to the along-strike shearing during reactivation of the fossil strike-slip mantle shear zone, reducing the strain localization within it, and (3) it better transmits stresses back to the mantle, thus if frictional weakening occurs in the upper crust, deformation in the crust far from the mantle shear zone results in strain delocalization in this latter. The two last effects lead to less efficient long-term strain localization in the entire lithosphere.

\section{Discussion}

\section{Validity and limitations of the model}

Comparisons of the present simulations with those from previous studies on CPOinduced viscous anisotropy in the mantle and on the effect of large-scale rheological heterogeneities on lithosphere deformation validate our work. The range of flow stresses in the aggregate-scale due to the presence of olivine CPO is consistent with the maximum viscous anisotropy produced by dislocation creep in upper mantle rocks (Mameri et al. 2019). The presence of fossilized olivine CPO in either the mantle shear zone or in its surroundings results in non-parallelism between principal strain and stress components, in agreement with fully-coupled VPSC-finite element models of extension of an isothermal plate with homogenous olivine CPO (Knoll et al. 2009). As in the models by Tommasi et al. (2001) and Tommasi et al. (2009), if the fossil mantle shear zone is oblique to the imposed mechanical load, along-strike shearing controls the reactivation of the fossil mantle shear zone. The stronger strain localization predicted in the simulations with a strong olivine CPO relatively to the previous works is consistent with the higher intensity of CPO used here. The present predictions for isotropic rheological heterogeneities agree with previous studies that examined the effects of large-scale isotropic rheological heterogeneities in both extensional and collisional intraplate settings (Dunbar \& Sawyer, 1989; Tommasi et al. 1995; Tommasi \& Vauchez, 1997; Brune et al. 2012). These studies demonstrated that weak heterogeneities always localize strain, with the intensity of the strain localization depending on the strength contrast relatively to the surroundings, but that oblique loading-geometries result in higher shear stress resolved along the maximum elongation of the heterogeneity, hence more effective strain localization.

The lithosphere has certainly large-scale heterogeneous lateral distribution of nonrandom olivine CPO. Teleseismic shear-wave splitting data indicate that the lithosphere is characterized by domains with coherent seismic anisotropy patterns (on the scale of hundreds 
of $\mathrm{km}$ ) and sharp changes (on the scale of tens of $\mathrm{km}$ ) of the orientation and intensity of the anisotropy ( $c f$. Shear-wave splitting database, http://splitting.gm.univ-montp2.fr/DB/). Although the teleseismic shear-wave splitting integrates seismic anisotropy all over the wave path, from the core-mantle boundary to the station, most anisotropy is produced in the upper $250 \mathrm{~km}$ of the mantle. Moreover, in continents these data document sharp variations within tens of $\mathrm{km}$ in the orientation and intensity of the anisotropy, pointing to a major contribution of the lithospheric mantle to the measured signal (Alsina and Snieder 1995). Thus, strain localization (or delocalization) resulting from lateral variations in viscous anisotropy (CPO) in the lithospheric mantle, as documented in the present models, are probably the rule rather than the exception on Earth.

Viscous anisotropy in the present models is parameterized for an olivine polycrystal deforming at high temperature, moderate pressure, and dry conditions, which favour intracrystalline deformation by dislocation glide in the [100] direction (e.g., Bai et al. 1991). However, if differential stresses are high or the temperature is low, as expected in the uppermost lithospheric mantle, the critical resolved shear stresses of the different olivine slip systems change and glide in the [001] direction is favoured (e.g., Durham and Goetze 1977; Demouchy et al. 2014). Thus, to model olivine deformation under low temperature, high stress conditions, a different parameterization of the viscous anisotropy is required. The transition from dominant [100] to [001] glide occurs at $\sim 1000^{\circ} \mathrm{C}$ under laboratory conditions (Durham and Goetze 1977; Demouchy et al. 2014). However, mantle mylonites in peridotite massifs record clear olivine CPO indicative of dominant [100] glide even when deformed at temperatures as low as $\sim 900^{\circ} \mathrm{C}$ (e.g., Frets et al. 2014). In peridotite mylonites deformed at lower temperatures (and higher stresses), activation of multiple slip systems, strong grain size reduction by dynamic recrystallization and increasing contribution of grain boundary processes results in weak olivine CPO, but still with a systematic concentration of [100] axes parallel to the stretching lineation (e.g., Newman et al. 1999; Hidas et al. 2016). This suggests that in nature the transition from [100] glide to dominant [001] glide occurs at much lower temperatures. In addition, comparison between olivine CPO developed in simple shear experiments on pure olivine synthetic aggregates (Bystricky et al. 2000; Hansen et al. 2012; Hansen et al. 2014) with olivine CPO developed in naturally deformed mantle rocks with variable pyroxene contents, as those in the studies cited above, corroborates that the presence of pyroxenes does not significantly modify the olivine CPO evolution in simple shear. By consequence, the parameterization used in the present simulations is probably valid 
for most of the lithospheric mantle.

Nevertheless, at low temperature and high stresses, dynamic recrystallization weakens the CPO and produces marked grain size reduction (e.g., Falus et al. 2011), allowing for higher contribution of diffusive and grain boundary-related processes. This should in turn result in weaker viscous anisotropy in the shallowest lithospheric mantle (Mameri et al. 2019), which would reduce the associated strain localization in the crust. However, inference of large volumes with weak olivine CPO within mantle shear zones in the shallow lithospheric mantle is at odds with the strong Pn-wave anisotropy measured in the vicinity of major strike-slip structures, such as the South Armorican shear zone (Judenherc et al. 2003), the San Andreas (Hearn et al. 1996) and the Alpine faults (Scherwath et al. 2002; Baldock and Stern 2005, Vauchez et al. 2012), which imply strong olivine CPO consistent with past strike-slip kinematics at sub-Moho depths in the shear zone, producing olivine CPO similar to those used in the modelled fossil shear zone.

The present models consider the crust as isotropic and homogeneous. Field observations show that strike-slip shear zones usually display a strong planar fabric at all depths due to development of both shape- and crystal-preferred orientation, which, in the crust, is often associated with a strong compositional banding. This fabric, in particular the orientation of phyllosilicates, should produce viscous anisotropy characterized by lower viscosity parallel to the shear zone foliation than the viscosity normal to it (Shea and Kronenberg 1993). We expect that this crustal anisotropy would enhance along-strike shearing in the lithospheric shear zone and, consequently, the strain localization relative to simulations with a mechanically isotropic crust. However, to confirm this prediction crustal viscous anisotropy would have also to be implemented in 3D geodynamical models. The approach presented in this work could be extended for crustal mechanical anisotropy with the advantage of requiring a simplified parameterization of the viscosity tensor thanks to a higher symmetry (transverse isotropy).

\section{Viscous anisotropy of fossil strike-slip mantle shear zones and the associated crustal response}

Until now, numerical models that investigated the role of olivine viscous anisotropy on the intraplate deformation using a 3D finite-element method considered only the mechanical response of the mantle (Knoll et al. 2009; Tommasi et al. 2009). These studies suggested that deformation in the mantle greatly depends on the olivine CPO intensity and orientation relatively to the imposed mechanical load. We have further examined the effect of 
viscous anisotropy in fossil strike-slip mantle shear zones on the intraplate deformation by analysing the associated crustal response. Our models show that the CPO-produced structural reactivation of mantle structures may produce strain localization in both ductile and brittle crust (Figure 3). The olivine CPO in the fossil mantle shear zone controls not only the strain localization, but also the strain regime in the entire lithosphere (Figure 5). The strain regime in the crust follows that in the fossil mantle shear zone. Reactivation of the fossil anisotropic mantle shear zone is systematically associated with shearing parallel to the strike of the fossil shear plane, which leads to transpression in both the crust and mantle when the plate is subjected to compression, or transtension when it is subjected to extension (Figure 5c). In the present models, vorticity is lower in the crust than in the mantle, but as discussed in the previous section, an anisotropic fabric in the lower crust, for instance due to mica CPO, would probably enhance the strike-slip component in the fossil shear zone.

Not surprisingly, the boundary conditions strongly affect CPO-induced structural reactivation in the lithosphere. The maximum strain localization due to a contrast in viscous anisotropy between a fossil strike-slip mantle shear zone and the surrounding mantle only occurs when the boundary conditions allow for full expression of the intrinsic viscous anisotropy of olivine. If the boundary conditions do not allow the development of shearing parallel to the strike of the fossil shear zone, as it is the case for simulations at oblique loading-geometries in which free-slip boundary conditions are imposed to the lateral boundaries of the model, the strain localization associated with CPO-induced viscous anisotropy is significantly reduced. Thus, CPO-induced structural reactivation will depend on the strength of the neighbouring domains. Presence of a stiff cold craton will tend to hinder reactivation, as this situation will be equivalent to the free-slip lateral conditions tested here. In contrast, weaker or similar strength neighbouring domains will allow for full expression of the CPO-induced viscous anisotropy. Regional seismic tomography models shows thermal (and rheological) heterogeneities at scales of tens to hundreds of $\mathrm{km}$ in the continental lithosphere (Fishwick et al. 2005; Pedersen et al. 2013), which suggest that in nature the lateral boundary conditions probably vary between the free-slip and P-litho end-members.

Feedbacks between the crust and the mantle affect the strain distribution in the lithosphere and modify the strain localization produced by lateral variations of olivine CPO in the mantle. If the crust is weak, the stress heterogeneity associated with reactivation of the fossil shear mantle zone, which is higher for a strong isotropic mantle rheology, results in effective strain localization in the crust. However, this strain localization decreases fast with 
increasing distance from the Moho. This result might nevertheless change if viscous anisotropy in the ductile crust is considered. If the crust is strong, the same stress heterogeneity at Moho levels results in weaker strain localization in the lowermost crust, but in better upward transmission of stresses due to efficient crust-mantle mechanical coupling. Consequently, the most effective strain localization in the entire lithosphere column (crust and mantle) is observed in simulations with a relatively strong crust and mantle. Variations through time in the strain repartition within the crust also affect the strain localization in the mantle. For instance, strain localization due to frictional weakening in the upper crust initially enhances the strain localization triggered by olivine viscous anisotropy in the mantle. However, if continued deformation leads to formation of faults elsewhere in the model, strain also delocalizes in the mantle.

\section{Olivine CPO fossilized in mantle shear zones: a possible trigger for linear arrays of intraplate seismicity}

Linear arrays of intraplate seismicity are a direct evidence of strain localization within otherwise stable continental interiors. Many of these enigmatic features are associated with long-lived, lithospheric-scale, strike-slip faults developed in ancient rifts or collisional belts (Sykes 1978; Storti et al. 2003), such as the localized seismicity along New Madrid and East Tennessee shear zones in the eastern North America (e.g., Johnson et al. 2014; Powell and Thomas 2016; Anglin 1984) or along the South Armorican shear zone in Brittany (e.g., Mazabraud et al. 2005; Mazzotti et al. 2020). Despite the different geological evolutions, analysis of seismic anisotropy observations around these intraplate seismically active zones (Judenherc et al. 2003; Long et al. 2016; Nyamwandha and Powell 2016) highlights the parallelism between the orientation of the mantle fabric, materialized by the orientation of the fast polarization direction of the fast split shear-waves, and the trend of the linear seismicity arrays (Figure 8). In both the New Madrid and South Armorican seismic zones, the presentday principal horizontal stresses are oblique to the orientation of the mantle fabric deduced from the seismic anisotropy measurements. Analysis of these data on the light of the presented anisotropic models leads us to propose that the development of these intraplate linear seismicity arrays was favoured by the oblique orientation of the fossil strike-slip mantle fabric relative to present-day stress field (Figure 8a). The predominance of strike-slip focal mechanisms in the New Madrid seismic zone (Mazzotti \& Townend 2010; Johnson et al. 2014) is consistent with the model predictions for loading at $\sim 45^{\circ}$ to a pre-existing strike-slip mantle fabric and lithostatic pressure boundary conditions (transpression with predominance 
of strike-slip deformation, Figures $\mathbf{4 b}$ and 5c). This is in agreement with the interpretation of reactivation of the Proterozoic Reelfoot rift as produced by right-lateral strike-slip motion along a northeast-oriented transform fault that formed the Paleozoic continental margin of southeastern Laurentia (Thomas 1991).

The mixed character (strike-slip and normal faulting) of the focal mechanisms in the South Armorican seismic zone (Mazabraud et al 2005a, Mazabraud et al 2005b), as observed for instance in the $\mathrm{Mw}=4.3$ Lorient earthquake located right atop the major fault trend (black star in Figure 8b; Perrot et al. 2005), requires a different orientation of the present-day stress field or of the pre-existing olivine CPO, leading to a more equilibrated repartition between shear parallel to the fossil mantle fabric and extension normal to it. The latter hypothesis (different orientation of the CPO) is at odds with the past Hercynian deformation history of the South Armorican shear zone, which had a clear dextral strike-slip kinematics and a vertical trend in the crust. Inversion of earthquakes focal mechanisms in the Armorican massif suggests nevertheless departure of the principal present-day compression axis in the vicinity of the South Armorican shear zone from the horizontal direction (Mazabraud et al. 2005a,b). This stress orientation, together with other regional-scale variations in the present-day stress field (Mazabraud et al. 2005b), may account for the mixed character of the earthquakes focal mechanisms in the region.

Triggering localized seismicity in the upper crust in response to strain localization due to $\mathrm{CPO}$-induced viscous anisotropy in the mantle requires a moderate to strong mechanical coupling between the mantle and crust. A relatively strong lower crust is required to effectively transfer stress between the mantle and upper crust (clutch tectonics of Tikoff et al. 2002). This interpretation is consistent with seismic tomography models that point to a relatively strong crust and a weak upper mantle beneath the New Madrid seismic zone (Zhan et al. 2016), and with depth-integrated strength models of Western Europe derived from crustal thickness and heat flow data, which predict relatively high crustal strengths in the Armorican Massif (Cloetingh et al. 2005). More effective mantle-crust mechanical coupling results in crustal strain focused in a thinner zone. According to this prediction, the narrower linear array of seismicity associated with the New Madrid shear zone compared to the relatively wider array in the South Armorican shear zone could reflect, at first order, a higher degree of crust-mantle mechanical coupling in the former (Figure 8).

Strong mechanical coupling results in a time-dependent behaviour and weaker longterm strain localization. Long-lived intraplate strain localization may, however, be favoured 
by activation of other strain weakening processes, such as shear heating, microstructural evolution, or focusing of fluids. For instance, seismicity in the New Madrid shear zone has been previously interpreted as due to localized thermal weakening of the lithosphere, based on heat flow data (Liu and Zoback 1997) and on low seismic velocities imaged in the mantle beneath it between 80 and $200 \mathrm{~km}$-depth (Chen et al. 2014). In the South Armorican shear zone, Mansard et al. (2018) proposed that the sheared middle crust has undergone significant weakening by grain size reduction and mica interconnection. These processes may add up to CPO-induced viscous anisotropy, allowing effective strain localization in the fossil strike-slip mantle shear zone for a wider range of loading-geometries (see Supplementary material Figure S3) and longer times.

\section{Conclusions}

We modelled the mechanical response of a continental plate containing a fossil strike-slip mantle shear zone with a 'wrench-type' olivine CPO (i.e. produced by horizontal shear on a vertical plane) using 3D elasto-viscoplastic finite-element models with an anisotropic viscous behaviour in the mantle. The anisotropic rheology produced by the CPO is defined by the Hill (1948) orthotropic yield criteria, with six constant material parameters obtained by fitting second-order viscoplastic self-consistent (SO-VPSC) simulations of deformed olivine polycrystals with relative slips system strengths derived from high temperature experiments in olivine single crystals. Strain localization and deformation regimes in the mantle and crust were examined as a function of the orientation of the mantle shear zone, its CPO intensity, the boundary conditions, and of the different isotropic part of the mantle and crust rheologies. The main conclusions are:

(1) The parameterized approach we developed effectively simulates the full (3D) anisotropic viscosity tensor associated with the orientation of olivine crystals in the mantle at relatively fast computation times (only a factor $\sim 2$ longer than equivalent simulations with an isotropic mantle rheology).

(2) Reactivation of a fossil strike-slip mantle shear zone, when controlled by viscous anisotropy, depends non-linearly on its orientation relative to a new stress field. Strain localization is most effective at $45^{\circ}$, where it is equivalent (or even stronger if the surrounding mantle is not isotropic) to the one obtained by imposing an isotropic weakening by a factor 100 on a domain with the same geometry and lateral boundary conditions. No reactivation is observed for fossil anisotropic 
strike-slip mantle shear zones oriented at $<30^{\circ}$ or $>60^{\circ}$ to the imposed shortening. This is in marked contrast with the effect of an isotropic rheological heterogeneity, which is reactivated at all orientations, although strain localization is also more effective when the load is oblique to the elongation of the tabular heterogeneity.

(3) The relation between the orientations of the olivine CPO in the fossil strike-slip mantle shear zone and of the imposed shortening affect the pattern of the strain localization in the entire lithosphere. The strain regime in the crust is controlled by the mantle deformation, with the CPO in the fossil strike-slip mantle shear zone favouring parallel-strike structural reactivation.

(4) Strain localization affects both the mantle and the isotropic crust atop the fossil mantle shear zone, but it is stronger in the mantle. In the reference simulation, the faults and shear zones that develop in the crust right above the mantle shear zone at $45^{\circ}$ deform on average $\sim 10$ times faster than the surrounding crust, whereas the mantle within the fossil shear zone deforms on average $\sim 30$ times faster than the surrounding mantle. The contrast between the crust and mantle behaviours is smaller for weaker viscous anisotropies (weaker olivine CPO).

(5) The strain distribution and the magnitude of strain localization depend mainly on the contrast in mechanical behaviour, which is function of the orientation and intensity of the olivine CPO within the mantle shear zone and in the surroundings. But it also strongly depends on the lateral boundary conditions, which may hinder the expression of the olivine viscous anisotropy within the mantle shear zone.

(6) Interactions between the mantle and the crust moderate strain localization in the entire lithosphere: (a) high strengths in the crust reduce strain localization in the mantle, but allow for more effective transmission of the deformation to the overlying crust; (b) further strain localization due to frictional weakening in the upper crust does enhance strain localization in the mantle; (c) strong mechanical coupling between the crust and mantle initially increases strain localization, but it produces a time-dependent behaviour with subsequent decrease in the strain localization; (d) weak (strong) mechanical coupling between the crust and mantle leads to more (less) heterogeneous strain localization acrodd the crust shear zone developed atop the fossil mantle shear zone.

(7) Spatial variations in CPO-induced viscous anisotropy may contribute to trigger linear seismicity belts in intraplate domains. 


\section{Acknowledgments}

We are grateful to Ricardo Lebensohn and Carlos Tomé for making the VPSC7c code freely available. We thank Alain Vauchez, Sylvie Demouchy, Catherine Thoraval, Sonia Ouadahi, and Marco Lopez-Sanchez for discussions. The authors thank Alain Vauchez, Sandra Piazolo, and an anonymous reviewer for insightful comments on the manuscript, and the associate editor for its effective handling. This project received funding from the European Union's Horizon 2020 research and innovation program under the Marie Sklodowska-Curie grant agreement No. 642029 (ITN-CREEP) and from the CNRS (France) and CONICET (Argentine) under the Projet International de Cooperation Scientifique MicroTex (No. 067785).

\section{Supplementary material}

The supplementary material of this article comprise three figures that presents:

(1) a comparison of strain localization profiles in the middle crust and in the shallow lithospheric mantle at steady-state for two different mesh resolutions (Figure S1);

(2) a simulation in which both the fossil mantle shear zone and the surrounding upper mantle are anisotropic and have olivine CPO-orientations leading to the maximum contrast in (viscous anisotropy) mechanical behaviour (Figure S2);

(3) a simulation in which a factor 100 isotropic weakening is imposed on a fossil mantle shear zone containing a strong olivine CPO (Figure S3); 

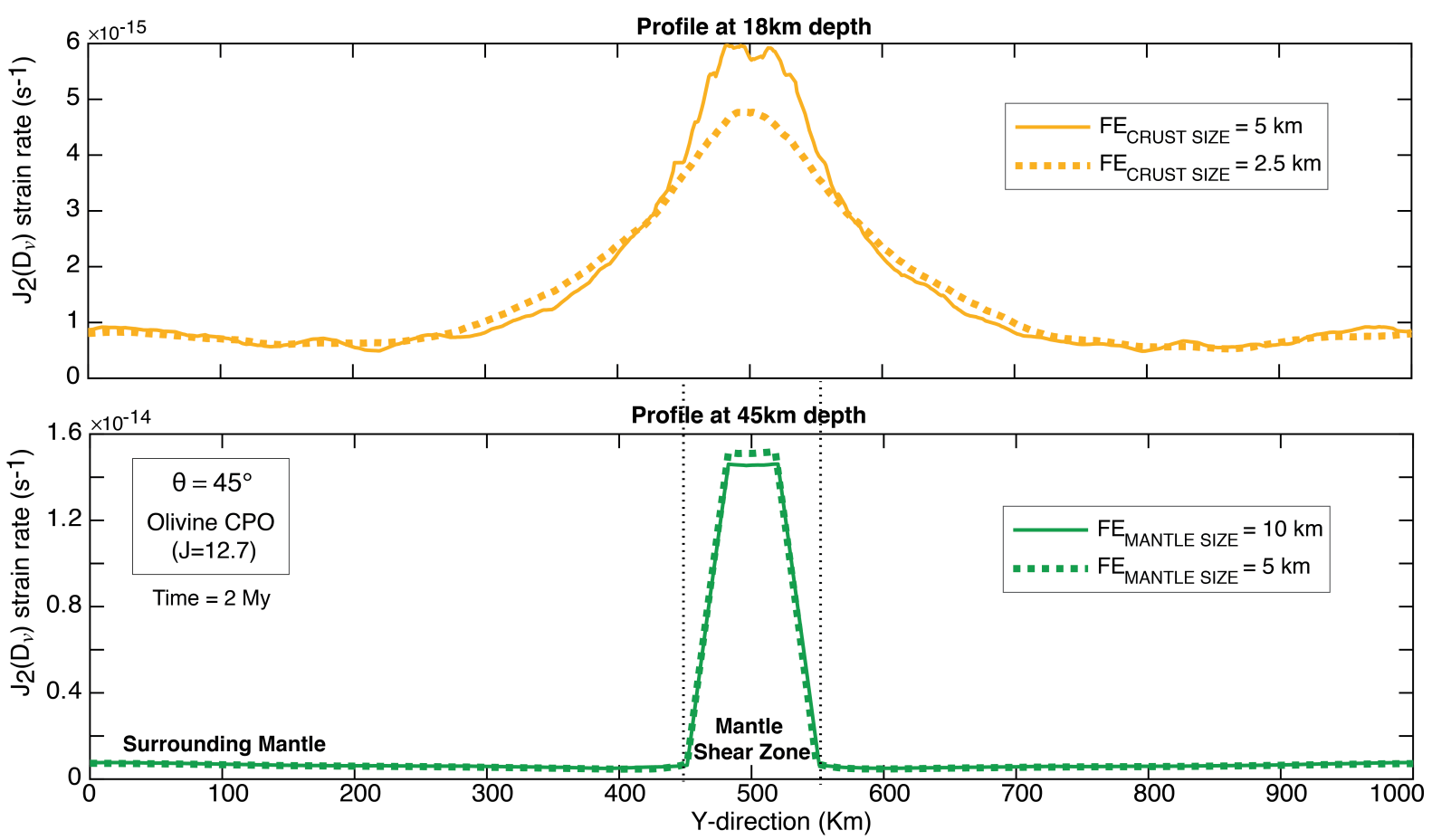

Figure S1: Effect of changing the finite-element (FE) mesh resolution on strain localization $\left(2^{\text {nd }}\right.$ invariant of the strain rate at steady-state) on the middle crust (yellow; profile at $18 \mathrm{~km}$ depth) and uppermost mantle (green; profile at $45 \mathrm{~km}$ depth) for the reference model (see Fig. 2 of the article). Continuous lines: FE mesh resolution used in the simulations presented in the article. Dashed lines: predictions for a two times higher FE mesh resolution. 


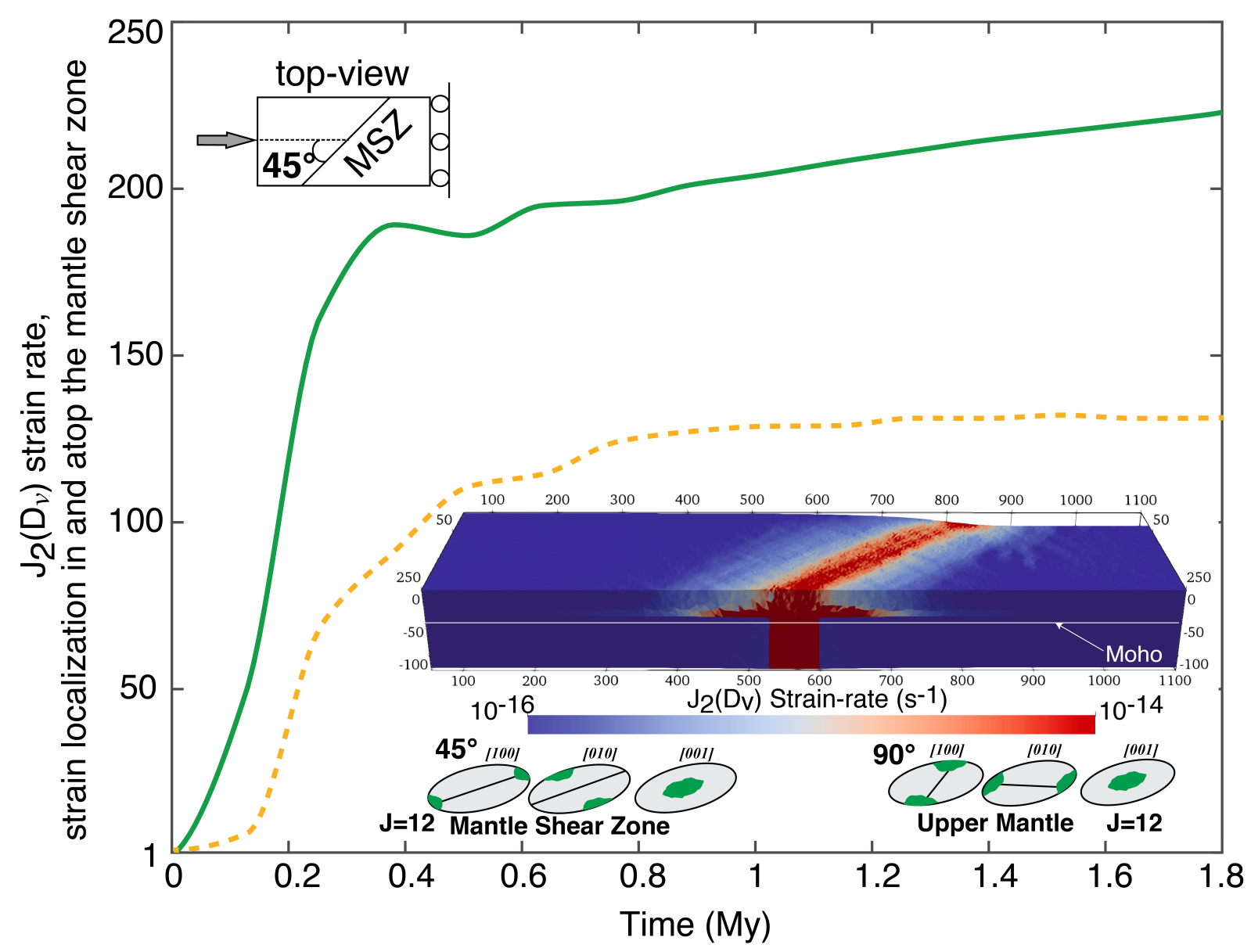

Figure S2: Simulation in which both the fossil mantle shear zone and the surrounding upper mantle are anisotropic and have olivine CPO leading to a maximum contrast in mechanical behaviour. Time evolution of the strain localization in the fossil shear zone, defined by the average of the $2^{\text {nd }}$ invariant of the strain rate $J_{2}\left(\mathrm{D}_{v}\right)$ within the fossil shear zone normalized by the same quantity averaged over the surrounding upper mantle. The fossil mantle shear zone shear plane, and consequently the olivine CPO within it, lies at $\theta=45^{\circ}$ to the compression axis, and in the surrounding upper mantle at $\theta=90^{\circ}$. Both mantle domains have a strong olivine CPO. P-litho conditions are imposed at the lateral boundaries. The insert displays the strain rate field $-J_{2}\left(\mathrm{D}_{v}\right)$ after 1.8 My of shortening. 


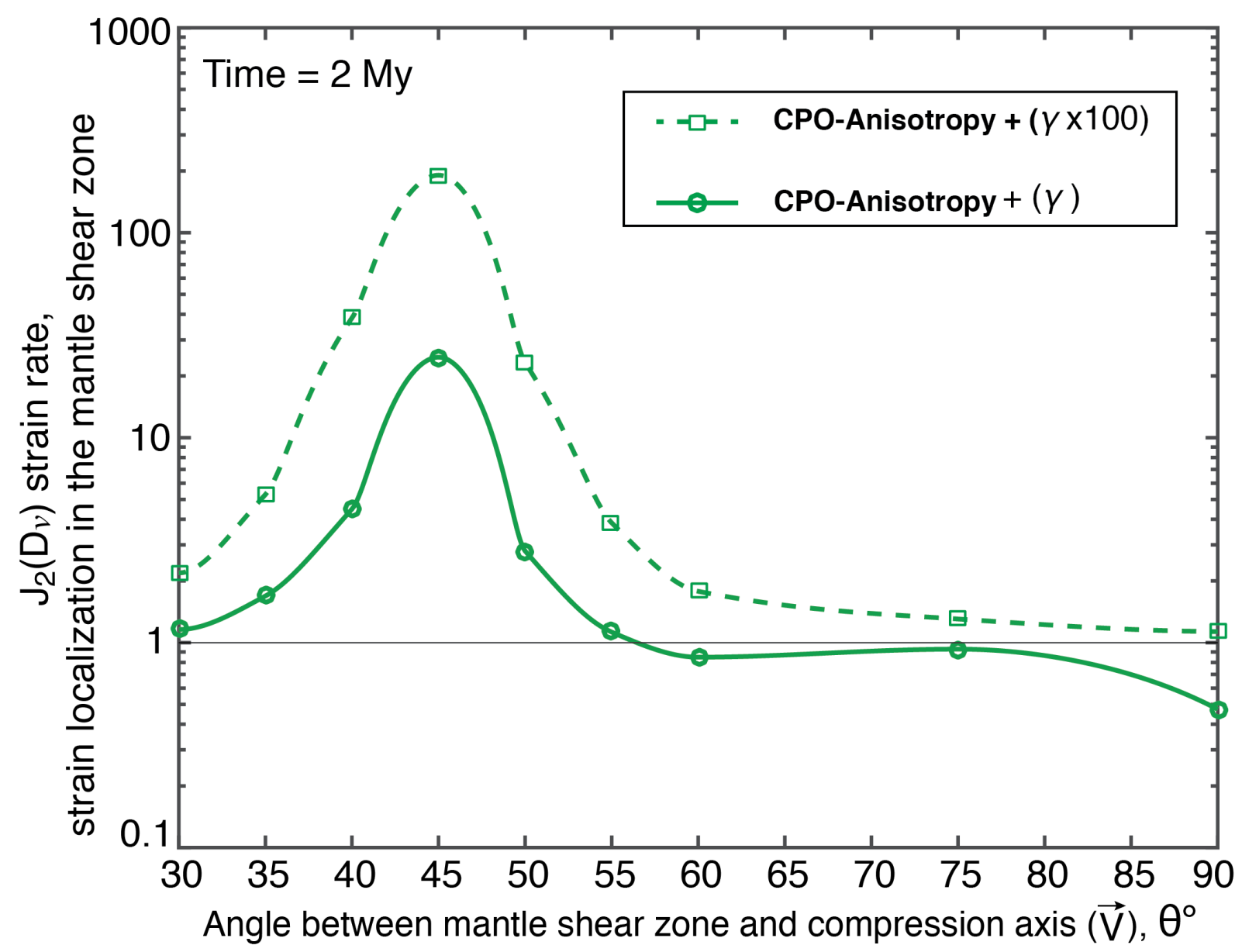

Figure S3: Strain localization at steady-sate ( $2 \mathrm{My})$ as a function of loading-geometry in a fossil strike-slip mantle shear zone containing a strong olivine CPO $(\mathrm{J}-i n d e x=12.7)$ on which is also imposed a factor 100 increase in the fluidity $(\gamma)$ (dashed line; squares) relatively to the strain localization resulting only from the CPO-induced anisotropy (continuous line; circles). Strain localization is quantified by the ratio between the average of the second-invariant of the strain rate tensor $J_{2}\left(\mathrm{D}_{v}\right)$ in the fossil mantle shear zone relatively to the surrounding upper mantle. 